\title{
Large Differences in the Optical Spectrum Associated with the Same Complex: The Effect of the Anisotropy of the Embedding Lattice
}

\author{
Aramburu, Jose Antonio; Garcia-Fernandez, Pablo; García Lastra, Juan Maria; Moreno, Miguel
}

Published in:

Inorganic Chemistry

Link to article, DOI:

10.1021/acs.inorgchem.7b00932

Publication date:

2017

Document Version

Peer reviewed version

Link back to DTU Orbit

Citation (APA):

Aramburu, J. A., Garcia-Fernandez, P., García Lastra, J. M., \& Moreno, M. (2017). Large Differences in the Optical Spectrum Associated with the Same Complex: The Effect of the Anisotropy of the Embedding Lattice. Inorganic Chemistry, 56(15), 8944-8953. https://doi.org/10.1021/acs.inorgchem.7b00932

\section{General rights}

Copyright and moral rights for the publications made accessible in the public portal are retained by the authors and/or other copyright owners and it is a condition of accessing publications that users recognise and abide by the legal requirements associated with these rights.

- Users may download and print one copy of any publication from the public portal for the purpose of private study or research.

- You may not further distribute the material or use it for any profit-making activity or commercial gain

- You may freely distribute the URL identifying the publication in the public portal 
Large differences in the optical spectrum associated to the same complex: the effect of the anisotropy of the embedding lattice

José Antonio Aramburu*1, Pablo García-Fernández¹ , Juan María García-Lastra², and Miguel Moreno ${ }^{1}$

${ }^{1}$ Departamento de Ciencias de la Tierra y Física de la Materia Condensada, Universidad de Cantabria, Avenida de los Castros s/n, 39005 Santander, Spain

${ }^{2}$ Department of Energy Conversion and Storage, Technical University of Denmark. Fysikvej 309, 2800 Kgs. Lyngby, Denmark 


\begin{abstract}
Transition metal complexes with a well-defined geometry are usually considered to display almost the same properties independently of the system where they are embedded. Here we show that the above statement is not true depending on the anisotropy of the host lattice, which is revealed in the form of the electric field created by the rest of lattice ions over the complex. In order to illustrate this concept we analyze the origin of the surprising large differences in the $d$-d optical transitions of two systems containing square-planar $\mathrm{CuF}_{4}{ }^{2-}$ complexes, $\mathrm{CaCuF}_{4}$ and center II in $\mathrm{Cu}^{2+}$-doped $\mathrm{Ba}_{2} \mathrm{ZnF}_{6}$, even though the $\mathrm{Cu}^{2+}{ }_{-} \mathrm{F}^{-}$distance difference is just found to be $1 \%$. Using a minimalist first-principles model we show that the different morphology of the host lattices creates an anisotropic field that red-shifts the in-vacuo complex transitions to the $1.25-1.70 \mathrm{eV}$ range in $\mathrm{CaCuF}_{4}$ while it blue-shifts them to the $1.70-3.0 \mathrm{eV}$ region in $\mathrm{Ba}_{2} \mathrm{ZnF}_{6}: \mathrm{Cu}^{2+}$. This particular example shows how the lattice anisotropy strongly alters the optical properties of a given transition metal complex. This knowledge opens a new path to tune the spectra of this large family of systems.
\end{abstract}

*email: aramburj@unican.es 


\section{Introduction}

Insulating materials containing Transition Metal (TM) cations are intensely studied as they display a wide range of chemical and physical properties that can be sensitive to external perturbation, in the form of either applied fields ${ }^{1-2}$, changes of temperature and pressure $^{3-4}$ or chemical tuning ${ }^{5-6}$, like replacement of ligands ${ }^{7}$. This behavior is well illustrated by the phenomenon known as spin-crossover where the magnetic state of the TM system can be altered upon heating, application of an elastic stress or irradiation ${ }^{8-12}$. In the latter case (see e.g. Ref. ${ }^{12}$ ), light absorption leads to a change in the electronic state of the TM that is accompanied by a geometrical relaxation that prevents the system from returning to its ground state. What this example comes to highlight is, on one hand, the large importance of the geometry of the system around the TM ion over its properties and, on the other, that optical spectroscopy is a very important tool associated to the chemistry of TM systems, both to characterize and manipulate their properties.

At the core of our understanding of the behavior of these systems is the idea that the TM ion forms, along with its close neighbors, the ligands, a chemical unit that has intrinsic properties and that is denominated complex. The theoretical foundation of this concept lies on the localization of valence electrons (also called active electrons) over the TM ion and its ligands ${ }^{13-14}$. Experimentally, this property is observed, for example, spectroscopically when studying the optical properties of a particular octahedral complex embedded in different cubic lattices. Good examples of this behavior are found, for instance, for $\mathrm{MF}_{6}{ }^{4-}$ complexes $(\mathrm{M}=\mathrm{Ni}, \mathrm{Mn})$ in pure and doped cubic fluoroperovskites ${ }^{14-20}$ or in $\mathrm{CrX}_{6}{ }^{3-}$ units $(\mathrm{X}=\mathrm{F}, \mathrm{Cl})$ formed in cubic elpasolites ${ }^{21-27}$. In such series of isomorphous lattices the optical absorption spectrum of a given complex is nearly unmodified with the lattice substitution as only the transitions that are dependent on the crystal-field splitting parameter, 10Dq, experience shifts smaller than $0.2 \mathrm{eV}$ due to changes of the metal-ligand distance, $\mathrm{R}$, smaller ${ }^{14,16}$ than $5 \%$. In this way, the concept of complex, not just as a stable chemical unit but also as a container of welldefined properties, has gained much weight since its inception.

However, successful this application of the concept of complex is, we believe important realizing its limits both for fundamental and practical reasons, since this could open new ways to control the properties of transition metal systems. In particular, we propose that the properties of a complex are transferable from a system to another only when the embedding media share similar morphological properties. On the contrary, when the embedding lattices are not isomorphous, the properties of the complex can change quite strikingly. A very visual example of this kind can be found at the $\mathrm{CrO}_{6}{ }^{9-}$ complex in $\mathrm{Al}_{2} \mathrm{O}_{3}$ and $\mathrm{Be}_{3} \mathrm{Al}_{2} \mathrm{Si}_{6} \mathrm{O}_{18}$, yielding ruby and emerald gemstones ${ }^{28-29}$, respectively. Even though the experimental metal-ligand distance is the same in both materials ${ }^{30-32}$ their colors are remarkably different. The origin of this effect is the internal electric field, $E_{R}(r)$, that the rest of lattice ions create on active electrons confined in the complex. This 
anisotropic field modifies the separation among states and thus the energies of optical transitions ${ }^{30}, 33$. In the case of ruby the modest energy shift ${ }^{30}$ on the cubic field splitting parameter, $10 \mathrm{Dq}$, due to $E_{R}(r)$ is around $0.2 \mathrm{eV}$, though sufficient to provoke the striking difference of color between this gemstone and emerald.

In this work we aim to quantify the effect of the anisotropy of the lattice, as materialized in the internal field $E_{R}(r)$, over the properties of the TM complex and check its possible limits. To do so we will look for complexes where the effect of the anisotropy is much stronger than in the cases discussed before involving six-fold coordinated complexes. Thus, instead of studying nearly octahedral complexes, we will discuss the properties of square-planar systems where the axial and equatorial directions are far from being equivalent. In particular, we will focus on two systems involving the same $\mathrm{CuF}_{4}{ }^{2-}$ complex, whose optical spectra are quite different. The first system is the $\mathrm{CuF}_{4}{ }^{2-}$ complex appearing in the pure compound ${ }^{34-36} \mathrm{CaCuF}_{4}(14 / \mathrm{mcm}$ space group, Fig. 1 left) while the second is the center II detected ${ }^{37}$ by electron paramagnetic resonance (EPR) and electron nuclear double resonance (ENDOR) in $\mathrm{Ba}_{2} \mathrm{ZnF}_{6}(14 / \mathrm{mmm}$ space group, Fig. 1 right) nominally doped with $3 \%$ of $\mathrm{CuF}_{2}$. In this case, $\mathrm{Cu}^{2+}$ enters an interstitial site of the $\mathrm{Ba}_{2} \mathrm{ZnF}_{6}$ host lattice ${ }^{38}$ and forms a $\mathrm{CuF}_{4}{ }^{2-}$ complex. ENDOR data shows no evidence for a distortion of the square-planar symmetry implying that the four $\mathrm{F}^{-}$ligands involved in $\mathrm{CuF}_{4}{ }^{2-}$ are equivalent ${ }^{37}$. In the dominant center formed in $\mathrm{Ba}_{2} \mathrm{ZnF}_{6}: \mathrm{Cu}^{2+}$ (center I) $\mathrm{Cu}^{2+}$ replaces $\mathrm{Zn}^{2+}$ thus giving rise to a sixfold coordinated $\mathrm{CuF}_{6}{ }^{4-}$ complex ${ }^{37}$, ${ }^{39}$, whose properties have previously been explored ${ }^{40}$.

Optical measurements carried out on $\mathrm{CaCuF}_{4}$ show ${ }^{37}$ the existence of three transitions in the $1.25 \mathrm{eV}-1.70 \mathrm{eV}$ domain (Fig. 2 top), assigned to the three $d$ - $d$ transitions expected for a tetragonal $\mathrm{CuF}_{4}{ }^{2-}$ complex. Concerning the optical spectrum of $\mathrm{Ba}_{2} \mathrm{ZnF}_{6}: \mathrm{Cu}^{2+}$ (centre II), there are also three transitions, which appear as shoulders and can be ascribed to $\mathrm{CuF}_{4}{ }^{2-}{ }^{-}$complexes ${ }^{39}$. However, such transitions are observed in the 1.7 $\mathrm{eV}$ - $3.0 \mathrm{eV}$ region in $\mathrm{Ba}_{2} \mathrm{ZnF}_{6}$ (Fig. 2 bottom) which, surprisingly, does not overlap with the domain where the $d$ - $d$ transitions of $\mathrm{CaCuF}_{4}$ are recorded. For this reason, it was early believed that the shoulder found at $\sim 1.74 \mathrm{eV}$ for $\mathrm{CuF}_{4}{ }^{2-}$ in $\mathrm{Ba}_{2} \mathrm{ZnF}_{6}$ can in fact be a $d$ - $d$ transition while those measured at $\sim 2.23 \mathrm{eV}$ and $\sim 2.98 \mathrm{eV}$ could be associated with charge transfer transitions ${ }^{39}$. In this work, we are going to use first-principles calculations to show that this is not the case and that the strong energy shift between the two sets of $d$ - $d$ transitions is due to the different nature of the anisotropic internal field, $E_{R}(r)$, in $\mathrm{CaCuF}_{4}$ and $\mathrm{Ba}_{2} \mathrm{ZnF}_{6}: \mathrm{Cu}^{2+}$.

The present work is organized as follows. An account of the employed computational methods is given in the next section. In addition to briefly commenting on experimental data supporting the formation of square-planar $\mathrm{CuF}_{4}{ }^{2-}$ complexes in $\mathrm{Ba}_{2} \mathrm{ZnF}_{6}: \mathrm{Cu}^{2+}$ the main results obtained in the present study are discussed in Section 3. For the sake of completeness, a general view on the role played by $E_{R}(\mathbf{r})$ on different systems is also provided at the end of that section. Finally, the discussion on the effect of the anisotropy 
of $E_{R}(r)$ on the properties of TM complexes and its implication are included in the last section.

\section{Computational details}

Periodic geometry optimizations on $\mathrm{CaCuF}_{4}$ and the center II of $\mathrm{Ba}_{2} \mathrm{ZnF}_{6}: \mathrm{Cu}^{2+}$ have been performed by means of the CRYSTAL14 code $^{41}$ under the framework of the Density Functional Theory (DFT). Calculations on the impurity system were performed using $2 \times 2 \times 1$ periodic supercells containing 72 ions. In order to be sure that impurity-impurity interactions between supercells are negligible selected calculations were repeated on $3 \times 3 \times 1$ supercells and the results were practically unmodified.

In the CRYSTAL code, the Bloch wavefunctions are represented by a linear combination of atomic orbitals which, in turn, are expressed as a combination of Gaussian basis functions. All ions have been described by means of basis-sets taken directly from the CRYSTAL's webpage ${ }^{42}$. In particular, we have used all-electron triple- $\zeta$ plus polarization (TZP) basis recently developed for Peitinger et al. ${ }^{43}$ for $\mathrm{Cu}, \mathrm{Zn}, \mathrm{Ca}$ and $\mathrm{F}$ and the pseudopotential basis HAYWSC-3111(2d)G_zagorac_2012 for Ba. Following previous works, we have used the B1WC hybrid exchange-correlation functional (including 16\% of Hartree-Fock exchange) that has shown to be able to reproduce with great accuracy the geometry and properties of a large number of both pure and doped crystals ${ }^{44}$. Similar results have been found using the PW1PW hybrid functional ${ }^{45}$ (including $20 \%$ of Hartree-Fock exchange).

For the calculation of the $d$-d electronic transitions we use an embedded cluster approach. Many advanced cluster embedding methods exist in the literature, from those focused on obtaining the exact electrostatic representation on the cluster ${ }^{46-47}$, to those trying to obtain a good representation of the electron density around the embedded region ${ }^{48-49}$, passing through intermediate solutions where several embedding layers taking into account short- and long-range interactions are considered. ${ }^{50-51}$ However, in order to clearly show the effect of the anisotropy of the electrostatic $E_{R}(r)$ field created by the rest of the crystal lattice ions on the complex, we use here just a $\mathrm{CuF}_{4}{ }^{2-}$ unit surrounded by point charges. The use of 5 atom clusters for describing the $d$ - $d$ transitions of these centers is consistent with the highly localized character of the unpaired electrons residing essentially in the $\mathrm{CuF}_{4}{ }^{2-}$ complex region. Supporting this view our periodic calculations yield a hole residing less than $2 \%$ outside that region. Calculations have been carried out with the Amsterdam density functional (ADF) code ${ }^{52}$, that allows performing DFT calculations on each specific electronic configuration and thus using a $\triangle$-SCF procedure to obtain the excitation energies. For this goal we have used the popular B3LYP hybrid functional ${ }^{53}$ in the spin-unrestricted Kohn-Sham formalism of the DFT and high-quality all-electron basis sets of triple- $\zeta$ plus polarization (TZP) type formed of localized Slater-type functions as implemented in the 2016.101 version of the ADF code. Tests carried out with larger clusters indicate that our 
results are stable when increasing the number of ions in the representation of the impurity's environment.

The internal electric field was generated by means of about 200 point charges with values previously fitted to reproduce the electric field corresponding to the infinite system $^{14,54-55}$.

\section{Results and Discussion}

Bearing in mind that the formation of square-planar $\mathrm{CuF}_{4}{ }^{2-}$ units is not very common it is worth mentioning the experimental data that support the formation of such complexes in $\mathrm{Ba}_{2} \mathrm{ZnF}_{6}: \mathrm{Cu}^{2+}$.

EPR data for center II in $\mathrm{Ba}_{2} \mathrm{ZnF}_{6}: \mathrm{Cu}^{2+}$ prove ${ }^{37}$ that the unpaired electron is located in an antibonding $b_{1 g}\left(x^{2}-y^{2}\right)$ orbital. The superhyperfine tensor shows the admixture of the $\mid x^{2}-y^{2}>$ wavefunction of copper with the $2 p(F)$ and $2 s(F)$ wavefunctions of four equivalent fluorine ions. In order to discard that such data cannot be associated with an elongated $\mathrm{CuF}_{6}{ }^{4-}$ unit the inspection of the experimental $g$-tensor conveys a useful information ${ }^{56}$. As shown in Table 1, $g_{\|-} g_{0}$ for elongated $\mathrm{CuCl}_{6}{ }^{4-}$ complexes $^{57-58}$ is $\sim 50 \%$ higher than for systems involving $\mathrm{CuCl}_{4}{ }^{2-}$ units ${ }^{59-60}$. In the same vein the values of $g_{\text {[阿- }} g_{0}$ measured for $\mathrm{CuF}_{6}{ }^{4-}$ in the cubic perovskites ${ }^{61-62} \mathrm{CsCdF}_{3}$ and $\mathrm{KZnF}_{3}$ are, respectively, $51 \%$ and $33 \%$ higher than the figure $g_{\|-} g_{0}=0.43$ reported ${ }^{37}$ for the center II in $\mathrm{Ba}_{2} \mathrm{ZnF}_{6}: \mathrm{Cu}^{2+}$. A similar situation holds when comparing the experimental $g_{\perp}-g_{0}$ values (Table 1 ). All these facts thus support that such a center actually involves a square-planar $\mathrm{CuF}_{4}{ }^{2-}$ unit.

As to the case of the pure compound $\mathrm{CaCuF}_{4} \mathrm{X}$-ray diffraction data clearly show the existence of $\mathrm{CuF}_{4}{ }^{2-}$ units that do not share common ligands (Fig. 1). The experimental $g_{\|-}$ $g_{0}=0.47$ and $g_{\perp}-g_{0}=0.07$ values $^{35}$ are consistent with this fact.

\subsection{Local Equilibrium Geometry for $\mathrm{CuF}_{4}{ }^{2-}$ units in $\mathrm{Ba}_{2} \mathrm{ZnF}_{6}$ and $\mathrm{CaCuF}_{4}$}

In order to check the reliability of the present periodic calculations we have determined, in a first step, the lattice parameters and the value of the $\mathrm{Cu}^{2+}-\mathrm{F}^{-}$distance, $\mathrm{R}$, for the $\mathrm{CaCuF}_{4}$ pure compound. Such values together with the distance between a $\mathrm{F}^{-}$ligand of $\mathrm{CuF}_{4}{ }^{2-}$ and the nearest $\mathrm{Ca}^{2+}$ ion (Fig. 1 ) and the $\mathrm{F}-\mathrm{Cu}-\mathrm{F}$ angle are reported in Table 2 and compared to experimental results ${ }^{36}$. It can be noticed that all calculated distances reproduce the experimental values with deviations smaller than $1 \%$. Moreover, we have verified that $d$ electrons from copper ions give a very sharp and narrow (about $1.5 \mathrm{eV}$ ) contribution to the density of states indicating that such electrons are well localized inside the $\mathrm{CuF}_{4}{ }^{2-}$ complexes.

In the same vein, the calculated lattice parameters for the $\mathrm{Ba}_{2} \mathrm{ZnF}_{6}$ host lattice (Fig. 2), $a$ $=4.093 \AA$ and $c=16.174 \AA$, differ by less than $1 \%$ with respect to experimental figures ${ }^{38}$, $a=4.101 \AA$ and $c=16.263 \AA$. 
In addition, a Bader charge analysis leaded to total ionic charges $\mathrm{Ca}^{+1.67}, \mathrm{Cu}^{+1.30}$ and $\mathrm{F}^{-0.74}$ for $\mathrm{CaCuF}_{4}$ and $\mathrm{Ba}^{+1.70}, \mathrm{Zn}^{+1.46}$ and $\mathrm{F}^{-0.81}$ for $\mathrm{Ba}_{2} \mathrm{ZnF}_{6}$, confirming that both materials have a significant ionic character.

Bearing these facts in mind, we have explored in a subsequent step the actual position and the associated equilibrium geometry of the $\mathrm{CuF}_{4}{ }^{2-}$ complex embedded in the $\mathrm{Ba}_{2} \mathrm{ZnF}_{6}$ host lattice. Taking into account the lattice structure of $\mathrm{Ba}_{2} \mathrm{ZnF}_{6}$ (Fig. 1) we have considered two possible empty sites where $\mathrm{Cu}^{2+}$ can be accommodated forming squareplanar $\mathrm{CuF}_{4}{ }^{2-}$ complexes: (1) $\mathrm{Cu}^{2+}$ enters the layer $\mathrm{B}$ at the interstitial site surrounded by four $\mathrm{F}^{-}$ions at a distance $\mathrm{R}=2.05 \AA$ in the perfect lattice (Fig. 1). Nevertheless, in this case there would be in the perfect lattice an axial $\mathrm{F}^{-}$ion at $2.13 \AA$ as well as another axial $\mathrm{Ba}^{2+}$ ion at a short distance (1.62 $\AA$ ) from the ideal interstitial site. (2) $\mathrm{Cu}^{2+}$ enters the layer $\mathrm{C}$ at the interstitial site surrounded by four $\mathrm{F}^{-}$ions at a distance $\mathrm{R}=2.05 \AA$ and two axial $\mathrm{Ba}^{2+}$ ions located at a distance of $2.456 \AA$ in the perfect lattice.

DFT calculations performed assuming that $\mathrm{Cu}^{2+}$ enters layer $\mathrm{B}$ converge slowly and give rise to a distorted pentacoordinated $\mathrm{CuF}_{5}{ }^{3-}$ complex which is not compatible with experimental findings $\mathrm{s}^{37}$ for centre II. By contrast, such calculations give rise to the formation of a stable $\mathrm{CuF}_{4}{ }^{2-}$ complex if $\mathrm{Cu}^{2+}$ occupies the interstitial position at the layer C. This result thus concurs with the conclusions derived from experimental EPR and ENDOR data ${ }^{37}$ supporting that centre $\mathrm{II}$ in $\mathrm{Ba}_{2} \mathrm{ZnF}_{6}: \mathrm{Cu}^{2+}$ actually involves an interstitial $\mathrm{Cu}^{2+}$ ion in layer $\mathrm{C}$.

The $\mathrm{M}$ - F distances ( $\mathrm{M}$ = interstitial site in layer $\mathrm{C}$ ) with the nearest $\mathrm{F}^{-}$ions for the perfect lattice are given in Table 3 together with the corresponding values for $\mathrm{M}-\mathrm{Ba}$ and $\mathrm{M}-\mathrm{Zn}$ distances. These distances are compared in Table 3 with those calculated when the $M$ site is already occupied by a $\mathrm{Cu}^{2+}$ ion. It should be noticed that the accommodation of $\mathrm{Cu}^{2+}$ in the $\mathrm{M}$ site requires a large outwards relaxation of two nearest $\mathrm{Ba}^{2+}$ ions equal to $22.5 \%$ while it is only $5.5 \%$ for closest $\mathrm{Zn}^{2+}$ ions lying in the layer plane. The outward relaxation of close $\mathrm{Ba}^{2+}$ and $\mathrm{Zn}^{2+}$ ions help to obtain a $\mathrm{Cu}^{2+}-\mathrm{F}^{-}$distance, $\mathrm{R}$, smaller than the $M$ - F distance ( $M=$ empty site) for the perfect lattice, equal to $2.055 \AA$. It should be remarked now that the calculated $\mathrm{Cu}^{2+}$ - $\mathrm{F}^{-}$distance, $\mathrm{R}=1.874 \AA$, for $\mathrm{CuF}_{4}{ }^{2-}$ in $\mathrm{Ba}_{2} \mathrm{ZnF}_{6}$ (Table 3) coincides, within $1 \%$, with that measured ${ }^{36}$ for the same complex in the $\mathrm{CaCuF}_{4}$ pure compound (Table 2 and Fig. 1). This relevant fact already stresses that the disparate optical spectra of $\mathrm{CuF}_{4}{ }^{2-}$ units in $\mathrm{CaCuF}_{4}$ and $\mathrm{Ba}_{2} \mathrm{ZnF}_{6}$ cannot be understood on the basis of a different value of the metal - ligand distance.

\subsection{Optical spectrum of $\mathrm{CuF}_{4}{ }^{2-}$ in $\mathrm{CaCuF}_{4}$ : red shifts due to the internal field}

In a first step, we have calculated the energy of three $d$ - $d$ transitions for $\mathrm{CaCuF}_{4}$ considering the isolated $\mathrm{CuF}_{4}{ }^{2-}$ unit and a value of the metal ligand distance $\mathrm{R}=1.89 \AA$. The results of calculations are displayed in Table 4 where they are compared to experimental findings ${ }^{35}$ for $\mathrm{CaCuF}_{4}$. It can immediately be noted that the experimental figures are significantly smaller than the transition energies calculated for an isolated 
complex. In particular, the experimental $\mathrm{a}_{1 \mathrm{~g}}\left(3 z^{2}-\mathrm{r}^{2}\right) \rightarrow \mathrm{b}_{1 \mathrm{~g}}\left(\mathrm{x}^{2}-\mathrm{y}^{2}\right)$ transition lies at 1.71 $\mathrm{eV}$ and thus it is $\sim 0.9 \mathrm{eV}$ smaller than the calculated energy $(2.58 \mathrm{eV})$ for the isolated complex. This fact thus stresses that the energy of $d$ - $d$ transitions in $\mathrm{CaCuF}_{4}$ cannot properly be understood just considering the isolated $\mathrm{CuF}_{4}{ }^{2-}$ complex.

It has been pointed out that the localization of active electrons in the complex does not necessarily mean that the optical transitions are understandable in terms of an isolated complex. Indeed, a charged complex has to be embedded in an insulating lattice and thus it can also be influenced by the electric field, $E_{R}(r)$, due to the rest of ions involved in the lattice ${ }^{14}$. As $E_{R}(r)$ has been shown ${ }^{30,33,63}$ to play a key role for explaining the different color of oxides containing $\mathrm{Cr}^{3+}$ or the $d$ - $d$ transitions in $\mathrm{K}_{2} \mathrm{ZnF}_{4}: \mathrm{Cu}^{2+}$ we have explored its influence in the case of $\mathrm{CaCuF}_{4}$.

The values of $d$ - $d$ transitions in $\mathrm{CaCuF}_{4}$ derived considering that the $\mathrm{CuF}_{4}{ }^{2-}$ unit is also subject to the internal electric field, $E_{R}(\mathbf{r})$, are displayed in Table 4 as well. It can be remarked that the calculated values are now much closer to experimental findings although with differences of the order of $0.1 \mathrm{eV}$, similar to those derived for fluorides containing $\mathrm{CuF}_{6}{ }^{4-}{ }^{-}$complexes $^{40,63}$. In particular, the calculated energy for the $\mathrm{a}_{1 \mathrm{~g}}\left(3 z^{2}-\mathrm{r}^{2}\right)$ $\rightarrow b_{1 g}\left(x^{2}-y^{2}\right)$ transition $(1.84 \mathrm{eV})$ is now close to the experimental value equal to 1.71 $\mathrm{eV}$. The reduction of $d-d$ transitions energy in $\mathrm{CaCuF}_{4}$ induced by the internal electric field can be understood looking at the shape of the potential, $V_{R}(r)$, generating $E_{R}(r)$. The form of the corresponding potential energy $(-e) V_{R}(r)$ felt by an electron is portrayed in Fig. 3 when the electron coordinate, $r$, moves either along a $\mathrm{Cu}^{2+}-\mathrm{F}^{-}$bond or perpendicularly to the plane containing the $\mathrm{CuF}_{4}{ }^{2-}$ unit. As shown in Fig. 3, in the first case $(-e) V_{R}(r)$ decreases as we move away from the copper site, $r=0$, while the opposite happens when we go along the perpendicular direction to $\mathrm{CuF}_{4}{ }^{2-}$. Therefore, the internal electric field in $\mathrm{CaCuF}_{4}$ is highly anisotropic as it tends to decrease the energy of the $b_{1 g}\left(x^{2}-y^{2}\right)$ planar orbital and, at the same time, to increase the energy of the $a_{1 g}\left(3 z^{2}-r^{2}\right)$ orbital lying mainly along the perpendicular direction to the $\mathrm{CuF}_{4}{ }^{2-}$ plane. Both facts explain, albeit qualitatively, the significant reduction of the $a_{1 g}\left(3 z^{2}-r^{2}\right) \rightarrow b_{1 g}\left(x^{2}-y^{2}\right)$ transition energy forced by the internal electric field in $\mathrm{CaCuF}_{4}$.

Although, in principle, all ions of the lattice contribute to $V_{R}(r)$ the shape of $V_{R}(r)-V_{R}(0)$ is mainly determined by the position and nature of ions lying close ${ }^{33}$ to those involved in the $\mathrm{CuF}_{4}{ }^{2-}$ unit. When the unpaired electron of the $\mathrm{CuF}_{4}{ }^{2-}$ complex lies in the planar $b_{1 g}\left(x^{2}-y^{2}\right)$ orbital the closest ions to a ligand $F^{-}$of the complex are two positive $\mathrm{Ca}^{2+}$ ions lying at a distance of $2.35 \AA$. By contrast, when the unpaired electron is placed in the axial $a_{1 g}\left(3 z^{2}-r^{2}\right)$ orbital the first ions that will act on such electronic density are two negative $\mathrm{F}^{-}$ions of the rest of the lattice lying at $2.80 \AA$. These facts allow us to qualitatively understand the anisotropy of $V_{R}(r)-V_{R}(0)$ when $r$ moves either along a $\mathrm{Cu}^{2+}$ - $\mathrm{F}^{-}$equatorial direction or along the axial direction perpendicular to the $\mathrm{CuF}_{4}{ }^{2-}$ plane.

\subsection{Optical spectrum of $\mathrm{CuF}_{4}{ }^{2-}$ in $\mathrm{Ba}_{2} \mathrm{ZnF}_{6}$ : blue shifts due to the internal field}


Once the equilibrium geometry around the interstitial $\mathrm{Cu}^{2+}$ ion in $\mathrm{Ba}_{2} \mathrm{ZnF}_{4}$ has been explored in section 3.1 we can now calculate the energy of three $d$ - $d$ transitions. Similarly to the procedure followed for $\mathrm{CuF}_{4}{ }^{2-}$ in $\mathrm{CaCuF}_{4}$, we have derived in a first step its value for the isolated $\mathrm{CuF}_{4}{ }^{2-}$ unit at the equilibrium metal - ligand distance $\mathrm{R}=1.874$ $\AA$. In a second step, we have included in the calculation the effects arising from the internal electric field, $\mathrm{E}_{\mathrm{R}}(\mathbf{r})$, on active electrons confined in the $\mathrm{CuF}_{4}{ }^{2-}$ complex. Results are displayed on Table 5.

The calculated $d$ - $d$ transitions for the isolated $\mathrm{CuF}_{4}{ }^{2-}$ unit in $\mathrm{Ba}_{2} \mathrm{ZnF}_{4}$ are almost equal to those derived in $\mathrm{CaCuF}_{4}$ although their energies are around $0.03 \mathrm{eV}$ higher following a reduction of $0.8 \%$ in the metal - ligand distance. Interestingly, such calculated energies for the isolated $\mathrm{CuF}_{4}{ }^{2-}$ unit are, in this case, smaller than the transition energies measured experimentally for $\mathrm{CuF}_{4}{ }^{2-}$ embedded in $\mathrm{Ba}_{2} \mathrm{ZnF}_{4}$. This situation is thus contrary to that encountered for $\mathrm{CaCuF}_{4}$. Nevertheless, as shown in Table 5, when the effects of the internal electric field, $E_{R}(r)$, are incorporated into the calculations the energy of the three $d$ - $d$ transition increases and the results are then closer to experimental findings. For instance, under the addition of $E_{R}(r)$ the calculated energy for the $b_{2 g}(x y) \rightarrow b_{1 g}\left(x^{2}-\right.$ $\left.y^{2}\right)$ transition increases by $0.2 \mathrm{eV}$ and thus coincides within $0.05 \mathrm{eV}$ with that estimated experimentally ${ }^{39}$. With regards to the highest $a_{1 g}\left(3 z^{2}-r^{2}\right) \rightarrow b_{1 g}\left(x^{2}-y^{2}\right)$ transition the inclusion of $E_{R}(r)$ increases its energy by $0.12 \mathrm{eV}$ with respect to that obtained for the isolated complex. In this case the calculated value for the $a_{1 g}\left(3 z^{2}-r^{2}\right) \rightarrow b_{1 g}\left(x^{2}-y^{2}\right)$ transition is about $8 \%$ smaller than the value estimated from the experimental optical absorption spectra for $\mathrm{Ba}_{2} \mathrm{ZnF}_{6}: \mathrm{Cu}^{2+}$. It should be noticed that such a transition is observed experimentally ${ }^{39}$ as a shoulder lying on a band whose intensity strongly grows when the energy increases. This fact, displayed in Fig. 2, can partially explain the $8 \%$ difference between the experimental estimation and the calculated value.

Therefore, the present calculations strongly support that the three transitions observed as shoulders in the optical absorption spectrum of $\mathrm{Ba}_{2} \mathrm{ZnF}_{6}: \mathrm{Cu}^{2+}$ are in fact the $d-d$ transitions of $\mathrm{CuF}_{4}{ }^{2-}$ units. The big difference with the optical spectrum of $\mathrm{CuF}_{4}{ }^{2-}$ in $\mathrm{CaCuF}_{4}$ can now be understood looking at the shape of $(-e) \mathrm{V}_{\mathrm{R}}(\mathbf{r})$ for $\mathrm{CuF}_{4}{ }^{2-}$ complexes placed in $\mathrm{Ba}_{2} \mathrm{ZnF}_{6}$, portrayed in Fig. 3. It can be remarked that when we move along an equatorial $\mathrm{Cu}^{2+}-\mathrm{F}^{-}$direction ( $r$ along $<100>$ directions) $(-e) \mathrm{V}_{\mathrm{R}}(\mathbf{r})$ is essentially flat while it decreases in the case of $\mathrm{CaCuF}_{4}$ (Fig. 3). Furthermore, when we move along the axial direction perpendicular to the $\mathrm{CuF}_{4}{ }^{2-}$ plane ( $r$ along $<001>$ directions) $(-e) \mathrm{V}_{\mathrm{R}}(\mathbf{r})$ decreases when the distance increases (Fig. 5). Thus the behavior of the anisotropic $V_{R}(r)$ potential for $\mathrm{Ba}_{2} \mathrm{ZnF}_{6}: \mathrm{Cu}^{2+}$ (centre II) is opposite to that found for $\mathrm{CaCuF}_{4}$ (Fig. 3).

Obviously, the origin of the anisotropy resides in the structure of the lattice and also the position occupied by the complex. We have verified that the form of $(-e) \mathrm{V}_{\mathrm{R}}(\mathbf{r})$ for $\mathrm{CuF}_{4}{ }^{2-}$ in $\mathrm{Ba}_{2} \mathrm{ZnF}_{6}$ greatly depends on the existence of two positive $\mathrm{Ba}^{2+}$ ions lying in axial positions as a result of the interstitial site occupied by $\mathrm{Cu}^{2+}$. Its influence on the energy of the $\mathrm{a}_{1 \mathrm{~g}}\left(3 z^{2}-r^{2}\right)$ orbital is however mitigated by the strong outwards relaxation of two 
$\mathrm{Ba}^{2+}$ ions, discussed in section 3.1, induced by the incorporation of $\mathrm{Cu}^{2+}$ at the empty site.

As shown in Fig. 3, when $r$ moves along $\langle 110\rangle$ then $(-e) V_{R}(r)$ also decreases when the distance increases, a matter related to the presence of four nearest $\mathrm{Zn}^{2+}$ ions in the plane containing the $\mathrm{CuF}_{4}{ }^{2-}$ complex. This fact thus explains the increase of the $b_{2 g}(x y) \rightarrow$ $b_{1 g}\left(x^{2}-y^{2}\right)$ transition energy by $0.2 \mathrm{eV}$ due again to the action of the internal electric field.

For the sake of clarity, we have also calculated the energy of the lowest allowed charge transfer transition for $\mathrm{CuF}_{4}{ }^{2-}$ in $\mathrm{Ba}_{2} \mathrm{ZnF}_{6}$ which is found to be located at $6.03 \mathrm{eV}$. This result confirms that any of optical transitions observed for $\mathrm{Ba}_{2} \mathrm{ZnF}_{6}: \mathrm{Cu}^{2+}$ cannot have a charge transfer origin as initially argued in $\operatorname{Ref}^{39}$. This conclusion is consistent with both the optical electronegativity scale by Jørgensen ${ }^{64}$ and results obtained for $\mathrm{CuCl}_{4}{ }^{2-}$ whose first allowed charge transfer transition appears ${ }^{65-66}$ at $3.2 \mathrm{eV}$. As the substitution of $\mathrm{Cl}^{-}$ by $\mathrm{F}^{-}$as ligand implies ${ }^{64}$ a blue shift of $\sim 3.4 \mathrm{eV}$ then the onset of charge transfer excitations for $\mathrm{CuF}_{4}{ }^{2-}$ is expected to be above $6 \mathrm{eV}$.

\subsection{Differences between $\mathrm{CuF}_{4}{ }^{2-}$ in $\mathrm{CaCuF}_{4}$ and $\mathrm{Ba}_{2} \mathrm{ZnF}_{6}$ : origin of the singularity}

Once we have proved that $\mathrm{CuF}_{4}{ }^{2-}$ in $\mathrm{Ba}_{2} \mathrm{ZnF}_{6}$ actually has a $d$ - $d$ spectrum very different from that of $\mathrm{CaCuF}_{4}$ it is worth pondering on the main reasons making possible this singular situation, described in the strongly different experimental spectra shown in Fig. 2.

There are three main factors behind such an unusual situation: (1) The main one is the anisotropic internal electric field that modifies, in first-order perturbation, the energy of involved orbitals giving rise to shifts of optical transitions ${ }^{30}$. These shifts are, in general, larger for square-planar than for sixfold coordinated complexes. So, for $\mathrm{CuO}_{4}{ }^{6-}$ complexes formed ${ }^{67-68}$ in $\mathrm{CaCuSi}_{4} \mathrm{O}_{10} \mathrm{E}_{\mathrm{R}}(\mathbf{r})$ gives rise to negative shifts ${ }^{69}$ up to $0.9 \mathrm{eV}$ on $d-d$ transitions, a situation similar to that found for $\mathrm{CaCuF}_{4}$. By contrast, for $\mathrm{CuF}_{6}{ }^{4-}$ in $\mathrm{K}_{2} \mathrm{ZnF}_{4}$ such shifts ${ }^{40,63}$ are smaller than $0.35 \mathrm{eV}$. (2) The character of the anisotropy depends on the structure of the embedding lattice and the position of the complex. So, in compounds like $\mathrm{CaCuSi}_{4} \mathrm{O}_{10}, \mathrm{BaCuSi}_{2} \mathrm{O}_{6}$ or $\mathrm{CaCuO}_{2}$ containing square-planar $\mathrm{CuO}_{4}{ }^{6-}$ complexes the internal electric field induces, in all cases, a red shift on the $d-d$ transitions ${ }^{69}$. For this reason, the energy of the $a_{1 g}\left(3 z^{2}-r^{2}\right) \rightarrow b_{1 g}\left(x^{2}-y^{2}\right)$ transition changes only by $0.3 \mathrm{eV}$ on passing from $\mathrm{CaCuSi}_{4} \mathrm{O}_{10}$ to $\mathrm{CaCuO}_{2}$. By contrast, $\mathrm{E}_{\mathrm{R}}(\mathbf{r})$ induces a red shift for $\mathrm{CaCuF}_{4}$ but a blue shift for $\mathrm{CuF}_{4}{ }^{2-}$ in $\mathrm{Ba}_{2} \mathrm{ZnF}_{6}$. This fact thus gives rise to shifts around $1 \mathrm{eV}$ when comparing the energy of the $\mathrm{a}_{1 \mathrm{~g}}\left(3 z^{2}-r^{2}\right) \rightarrow b_{1 g}\left(x^{2}-y^{2}\right)$ transition in both systems. (3) The internal field has a stronger effect on optical transitions involving jumps between two states belonging to a different configuration. Although this condition is well fulfilled by the three transitions explored for $\mathrm{CuF}_{4}{ }^{2-}$ in $\mathrm{Ba}_{2} \mathrm{ZnF}_{6}$ and $\mathrm{CaCuF}_{4}$ this is not the case for octahedral $d^{3}$ or $d^{5}$ complexes where there are excited states with the same electronic configuration of the ground state but a different spin ${ }^{17}$, 19,70 . The energy of such excitations are weakly affected by the internal electric field as 
the electronic density is modified by the addition of $E_{R}(r)$ only in second-order perturbations ${ }^{71}$. The ${ }^{2} \mathrm{E} \rightarrow{ }^{4} \mathrm{~A}_{2}$ crystal-field transition of $\mathrm{Cr}^{3+}$ in oxides and, to less extent, the ${ }^{6} A_{1} \rightarrow{ }^{4} A_{1}$ transition of octahedral $\mathrm{Mn}^{2+}$ complexes, are good examples of that behavior $^{71}$.

\subsection{Role of the internal electric field on optical properties: general considerations}

The present results emphasize the importance of the $E_{R}(r)$ field to obtain a correct quantitative understanding of the properties of TM complexes without the need to use any fitting parameter, i.e. completely from first-principles. For this reason, we cannot discard a priori the influence of $E_{R}(r)$ on the electronic states of a complex unless we previously prove that it is negligible. This means that, in general, there are two contributions ${ }^{33,40}$ to the separation between the levels of a complex and that critically determine, for example, the energy, $E$, of an optical transition corresponding to an axial TM system embedded in an insulating lattice

$$
E=E_{\text {int }}\left(\mathrm{R}_{\mathrm{eq}}, \mathrm{R}_{\mathrm{ax}}\right)+E_{\mathrm{ext}}
$$

Here, the first quantity means the intrinsic contribution coming from the isolated complex, which depends on metal-ligand distances, $R_{\mathrm{eq}}$ and $\mathrm{R}_{\mathrm{ax}}$, while the second one, the extrinsic contribution, arises from the effects due to the internal electric field $E_{R}(r)$.

It is firstly important noting that $E_{R}(r)$ is anisotropic even in cubic lattices. Owing to this fact the value of the crystal-field splitting parameter, $10 \mathrm{Dq}$, measured for $\mathrm{Cr}^{3+}$-doped the cubic MgO lattice, where $R_{a x}=R_{e q}=R$, is blue shifted ${ }^{33}$ by $0.2 \mathrm{eV}$ due to the action of $E_{R}(r)$ leading to a final $10 \mathrm{Dq}$ value that is equal to that measured ${ }^{29}$ for the emerald gemstone, $\mathrm{Be}_{3} \mathrm{Si}_{6} \mathrm{Al}_{2} \mathrm{O}_{18}: \mathrm{Cr}^{3+}$. This fact is, in principle, surprising as the $\mathrm{Cr}^{3+}-\mathrm{O}^{2-}$ distance in emerald ${ }^{30-31}(R=1.97 \AA)$ is smaller than that for the cubic center ${ }^{33}$ in $\mathrm{MgO}^{-\mathrm{Cr}^{3+}}(\mathrm{R}=$ $2.03 \AA$ ).

An exception are materials with perovskite ${ }^{14}$ and elpasolite structures ${ }^{72}$, where the $E_{R}(\mathbf{r})$ field is found to be very flat in all directions thus implying that optical transitions can be well understood only through the isolated complex. For this reason, the experimental $10 \mathrm{Dq}$ values derived for $\mathrm{MnF}_{6}{ }^{4-}$ complexes in fluoroperovskites directly reflect the equilibrium $\mathrm{Mn}^{2+}-\mathrm{F}^{-}$distance ${ }^{16,19}$. A similar situation holds when we consider a $\mathrm{CrF}_{6}{ }^{3-}$ or $\mathrm{CrCl}_{6}{ }^{3-}$ complex ${ }^{21-24,27}$ placed in different elpasolite lattices. Nevertheless, this idea is no longer true when we compare two host lattices that are not isomorphous as we have discussed for the 10Dq value ${ }^{33}$ for emerald, MgO or perovskite-based systems or as we have proved in sections 3.2 and 3.3 for $\mathrm{Cu}^{2+}$ square-planar complexes.

A significant field of application for these ideas can be found in the spectroscopic properties of $M X_{6}$ complexes $\left(M=d^{9}\right.$ ion, $X=$ halide) in non-cubic host lattices that have often been explained on the basis of a Jahn-Teller effect including extra empirical parameters and neglecting any influence of $E_{R}(r)$. A relevant example of this procedure concerns the $\mathrm{CuF}_{6}{ }^{4-}$ complex embedded in the tetragonal $\mathrm{K}_{2} \mathrm{ZnF}_{4}$ lattice involving $\mathrm{ZnF}_{6}{ }^{4-}$ 
units, which are practically perfect octahedra. Despite this fact the hole in $\mathrm{K}_{2} \mathrm{ZnF}_{4}: \mathrm{Cu}^{2+}$ is placed in the $\mathrm{a}_{1 \mathrm{~g}}\left(3 z^{2}-r^{2}\right)$ orbital ${ }^{73}$ and not in the $b_{1 \mathrm{~g}}\left(x^{2}-y^{2}\right)$ one, such as it is found for $\mathrm{Cu}^{2+}$-doped cubic perovskites like $\mathrm{KZnF}_{3}$ or $\mathrm{CsCdF}_{3}$ where a static Jahn-Teller effect takes place ${ }^{61-62}$. This remarkable difference reflects that in $\mathrm{K}_{2} \mathrm{ZnF}_{4}: \mathrm{Cu}^{2+}$ the internal field alone, displaying a tetragonal symmetry, produces an extrinsic gap $\Delta_{\mathrm{ext}}=0.35 \mathrm{eV}$ between $b_{1 g}\left(x^{2}-y^{2}\right)$ and $a_{1 g}\left(3 z^{2}-r^{2}\right)$ orbitals when the $\mathrm{CuF}_{6}{ }^{4-}$ complex is octahedral $\left(R_{a x}=R_{\text {eq }}\right)$, placing the $a_{1 g}\left(3 z^{2}-r^{2}\right)$ orbital above ${ }^{40,63}$. Thus, this extrinsic gap breaks the orbital degeneracy that should appear in a Jahn-Teller system when $\mathrm{R}_{\mathrm{ax}}=\mathrm{R}_{\text {eq }}$. By contrast, in $\mathrm{KZnF}_{3}: \mathrm{Cu}^{2+}$ that extrinsic gap is null 40,74 as a result of the cubic symmetry of $E_{R}(\mathbf{r})$ and the equilibrium geometry is the result of a static Jahn-Teller effect. The existence of an extrinsic gap in $\mathrm{K}_{2} \mathrm{ZnF}_{4}: \mathrm{Cu}^{2+}$, but not in in $\mathrm{KZnF}_{3}: \mathrm{Cu}^{2+}$, also explains why the absolute value of the gap, $|\Delta|$, measured at the equilibrium geometry is clearly higher for the former system ${ }^{75}(\Delta=$ $0.70 \mathrm{eV}$ ) than for the latter where optical absorption data reveal ${ }^{76}$ that $|\Delta|$ should be below $0.5 \mathrm{eV}$. These results are in agreement with first principles DFT calculations ${ }^{74}$ yielding $\Delta=-0.398 \mathrm{eV}$ for $\mathrm{KZnF}_{3}: \mathrm{Cu}^{2+}$. Despite these arguments, it is said in a recent paper ${ }^{77}$ that the properties of $\mathrm{K}_{2} \mathrm{ZnF}_{4}: \mathrm{Cu}^{2+}$ and $\mathrm{KZnF}_{3}: \mathrm{Cu}^{2+}$ can be understood on the same grounds, thus ignoring the effects of the tetragonal internal field in the former system. This surprising statement is based on an assumed experimental value $|\Delta|=0.62$ $\mathrm{eV}$ for $\mathrm{KZnF}_{3}: \mathrm{Cu}^{2+}$, which, if correct, should be very close to $\Delta=0.70 \mathrm{eV}^{\text {measured }}{ }^{75}$ for $\mathrm{K}_{2} \mathrm{ZnF}_{4}: \mathrm{Cu}^{2+}$. However, that assumption is not supported at all by experimental data ${ }^{76}$ and theoretical calculations ${ }^{74}$ on $\mathrm{KZnF}_{3}: \mathrm{Cu}^{2+}$ and thus it leads to a wrong conclusion.

The internal field, $E_{R}(r)$, not only plays a key role for understanding ${ }^{63,78}$ why $\mathrm{K}_{2} \mathrm{MgF}_{4}: \mathrm{Ni}^{+}$ has surprisingly a hole ${ }^{79}$ in $b_{1 g}\left(x^{2}-y^{2}\right)$ but also for explaining the eventual failure of various empirical rules widely used in the realm of TM complexes. For instance, one would expect that, according to the spectrochemical series ${ }^{64,80}$, the energy of three $d$ - $d$ transitions of $\mathrm{CuX}_{4}{ }^{2-}(\mathrm{X}=\mathrm{F}, \mathrm{Cl})$ complexes would decrease when fluorine is replaced by chlorine as ligand. However, the three $d$ - $d$ transitions measured for $\mathrm{CuCl}_{4}{ }^{2-}$ complexes in $(\mathrm{N}-\mathrm{mpH})_{2} \mathrm{CuCl}_{4}$ are found ${ }^{81}$ at $1.55,1.77$ and $2.11 \mathrm{eV}$ and thus all of them are lying above the corresponding transitions observed in $\mathrm{CaCuF}_{4}$ (Table 4). Obviously, the strong red shift induced by $E_{R}(r)$ on optical transitions of $\mathrm{CaCuF}_{4}$, discussed in section 3.2, plays an important role for explaining this anomaly.

It is worth noting that the potential $V_{R}(r)$ created by the internal field $E_{R}(r)$ is different from the so-called Madelung potential, $V_{M}(0)$. The last one is the electrostatic potential created by all the ions in the lattice except the one where the potential is calculated on, while $V_{R}(\mathbf{r})$ is the electrostatic potencial (on an electron in $\mathbf{r}$ position) created by all ions outside the complex, i.e. it does not include the field created by the ligands. The effect of $V_{R}(r)$, particularly that related to the anisotropy, is connected to its variation at the metal-to-ligand bond region that allows observing different effects on different orbitals. ${ }^{30,33}$ When $\mathbf{r} \approx 0$ (that is, the electron is almost on the metal of the complex) we 
have $V_{R}(r) \approx V_{M}(0)$, and its main effect would be a rigid shift of all the $3 d$ levels of the ion.

For compounds with a significant ionic character, it has been found that the shape of $E_{R}(r)$ is nearly unmodified when replacing the actual charges on ions by the nominal ones. Accordingly, the extrinsic contribution to the $b_{1 g}\left(x^{2}-y^{2}\right) \rightarrow a_{1 g}\left(3 z^{2}-r^{2}\right)$ transition in $\mathrm{K}_{2} \mathrm{CuF}_{4}$ is found to be ${ }^{74}$ nearly insensitive to the replacement of calculated charges by the nominal charges.

Finally, it is worth stressing that Eq. (1) essentially assumes that, in any host lattice, active electrons are always lying in the complex and thus there is not any flow of charge to close ions of the complex ${ }^{30}$. Experimentally, this circumstance has been well proved by means of the ENDOR technique in cases ${ }^{82-84}$ like ruby, $\mathrm{MgAl}_{2} \mathrm{O}_{4}: \mathrm{Cr}^{3+}$ or $\mathrm{KMgF}_{3}: \mathrm{Mn}^{2+}$. Under that situation, the optical properties of a given complex can vary either due to changes of the metal ligand distance or the different shape of $E_{R}(r)$ induced by lattice substitution. Obviously, this kind of analysis cannot be applied when comparing two complexes where the number or the nature of ligands is not preserved, such as it happens when considering isolated $\mathrm{CuF}_{6}{ }^{4-}$ and $\mathrm{CuF}_{4}{ }^{2-}$ units that are actually different. Indeed the removal of two axial ligands in $\mathrm{CuF}_{6}{ }^{4-}$ for obtaining the square-planar $\mathrm{CuF}_{4}{ }^{2-}$ unit already involves a drastic change in the order of d-orbitals and the electronic density.

\section{Final Remarks}

In this work we have demonstrated that, when studying the properties of a transition metal complex, it is crucial to consider the anisotropy of the lattice that takes the form of an internal field $E_{R}(r)$ created by the ions of the lattice not belonging to the complex. If we designate by $\phi_{i}$ an orbital of the complex, the energy shift due to the $V_{R}(r)$ potential is just determined, in first order perturbation ${ }^{30}$, by $\left\langle\phi_{i}\left|V_{R}(\mathbf{r})-V_{R}(0)\right| \phi_{i}>\right.$ and thus reflects the anisotropy of both $V_{R}(r)$ and the electronic density. Accordingly, the biggest changes in an optical transition $\phi_{\mathrm{i}} \rightarrow \phi_{\mathrm{j}}$ appear when the involved orbitals are placed in regions where $V_{R}(r)-V_{R}(0)$ looks very different. We have illustrated these ideas studying the properties of $\mathrm{CuF}_{4}{ }^{2-}$ complexes with very similar metal-ligand distances in two different lattices, $\mathrm{CaCuF}_{4}$ and $\mathrm{Cu}^{2+}$-doped $\mathrm{Ba}_{2} \mathrm{ZnF}_{6}$. We observed that the remarkably different optical spectra of these systems ${ }^{35}, 39$, that had led in the past to suggest that the transitions in $\mathrm{Ba}_{2} \mathrm{ZnF}_{6}: \mathrm{Cu}^{2+}$ had a charge-transfer character ${ }^{39}$, involve in both cases $\mathrm{d}$-d transitions. This central result is supported by calculations where, aside from a full quantum-mechanical description of the complex, a point-charge electric field $E_{R}(r)$ is simply added.

These minimalist calculations highlight the usefulness of the transition metal complex as a unit where the active electrons are localized. Moreover, they show a clear limitation in a very widespread application of the TM complex concept: not all the properties of the complex are intrinsic to it since the lattice anisotropy also plays an important role in 
them. While the origin of the interactions is of a completely different nature the anisotropy in the aggregation of the units forming molecular crystal is also found to play an important role in the optical properties of excitons since, for example, the axial versus in-plane exchange interactions in $\pi-\pi$ systems will clearly differ. ${ }^{85}$

It is important to note here that although the cubic lattices are usually considered as isotropic, due to the sphere-like symmetry of all rank-2 tensors like the dielectric tensor, this is not the case for the internal electric field, $E_{R}(r)$, felt by a complex embedded in such a lattice that exhibits full cubic symmetry, i.e., lower than spherical. For this reason, the optical properties of complexes in perfect cubic lattices reflect, in general, the expected anisotropy of $E_{R}(r)$. Good examples of this effect are found in host lattices displaying a rock salt ${ }^{33}$ or an inverted perovskite structure ${ }^{71,86}$, while cubic perovskites and elpasolites are an exception as $E_{R}(r)$ is very flat in the whole complex region ${ }^{14,72}$. Thus, in cubic systems, as $\mathrm{MgO},<100>$ and $<111>$ directions - that coincide, respectively, with the orientation of $e_{g}$ and $t_{2 g}$ orbitals - are not equivalent, a fact that opens a pathway to provide an extrinsic contribution ${ }^{33}$ to $10 \mathrm{Dq}$ due to the anisotropy of $E_{R}(r)$.

This difference is more evident for six-coordinated quasi-octahedral complexes in tetragonal and hexagonal lattices where the existence of a preferential axis is evident. However, calculations consistently show that the shifts in optical transitions obtained for these systems are small ${ }^{40}$, of the order of a few tenths of an $\mathrm{eV}$, when compared to the larger shifts found in square-planar systems where equatorial and axial directions are clearly different and anisotropy is openly displayed.

A further parallelism can be drawn between our application of the lattice anisotropy with the sign of the axial zero-field-splitting parameter, $D$, that measures magnetic anisotropy in TM complexes that have a spin quantum number $S>1 / 2$. In the same way that $E_{R}(r)$ lowers the energy of mainly axial orbitals in $\mathrm{Ba}_{2} \mathrm{ZnF}_{6}: \mathrm{Cu}^{2+}$ (center II) and equatorial orbitals in $\mathrm{CaCuF}_{4}, \mathrm{D}<0(\mathrm{D}>0)$ denotes the existence of an easy magnetic axis (plane) that is associated with the reduction of the energy of the states with a magnetic moment projected along that direction. Thus, in the same way that a strong effort is being put into the manipulation of the magnetic anisotropy of a system, the use of the lattice anisotropy can be used to tune the properties of TM complexes. In fact, subtle changes of orbital energies associated to the cubic to nearly square-planar configuration ${ }^{87-88}$ of $\mathrm{Fe}^{+}$-doped $\mathrm{SrCl}_{2}$ have been shown to be behind the origin of the huge magnetic anisotropy in this system ${ }^{89}$.

The importance of lattice anisotropy is not limited to explain the spectroscopic properties of embedded complexes but can also play a key role for understanding the electronic and geometrical structure of TM compounds. Along this line, it has been shown that the nature of the electronic ground state and the associated orbital ordering of compounds like $\mathrm{K}_{2} \mathrm{CuF}_{4}$ or $\mathrm{La}_{2} \mathrm{CuO}_{4}$ are deeply influenced by the shape of the internal 
electric field which in turns is shown by particular antiferro- and ferrodistortive patterns in the geometry of these systems ${ }^{90}$.

It is worth noting now that similar issues are well-known to arise in biological chromophores ${ }^{91-92}$ but are less documented in the solid-state community. In this sense recent papers deal with the importance of the electrostatic field over chromophores, like those created by amino acids in the opsin protein over the retinal chromophore ${ }^{92}$, a key feature to understand human vision, or the mechanism for light emission in the firefly luminescent protein. ${ }^{91}$

In summary, we have shown the importance of the lattice anisotropy as a key concept to understand transition metal complexes in crystals. This phenomenon is displayed even in systems believed to be "isotropic" and can be used to chemically modulate a wide-range of properties in this important family of compounds.

Further work on electronic and structural properties of compounds containing $\mathrm{d}^{9}$ cations is now underway.

\section{Acknowledgments}

The authors are indebted to Prof.M.T Barriuso for her help in the first steps of this work. The support by the Spanish Ministerio de Ciencia y Tecnología under Projects FIS201230996 and FIS2015-64886-C5-2-P is acknowledged. 


\section{References}

1. Birol, T.; Benedek, N. A.; Das, H.; Wysocki, A. L.; Mulder, A. T.; Abbett, B. M.; Smith, E. H.; Ghosh, S.; Fennie, C. J., The Magnetoelectric Effect in Transition Metal Oxides: Insights and the Rational Design of New Materials from First Principles. Curr. Opin. Solid State Mater. Sci. 2012, 16, 227-242.

2. Gong, Z.; Liu, G.-B.; Yu, H.; Xiao, D.; Cui, X.; Xu, X.; Yao, W., Magnetoelectric Effects and Valley-Controlled Spin Quantum Gates in Transition Metal Dichalcogenide Bilayers. Nature Communications 2013, 4, 2053.

3. Li, M.; Dai, J.; Zeng, X. C., Tuning the Electronic Properties of Transition-Metal Trichalcogenides Via Tensile Strain. Nanoscale 2015, 7, 15385-15391.

4. Park, J. H.; Coy, J. M.; Kasirga, T. S.; Huang, C.; Fei, Z.; Hunter, S.; Cobden, D. H., Measurement of a Solid-State Triple Point at The Metal-Insulator Transition in $\mathrm{VO}_{2}$. Nature 2013, $500,431-434$.

5. Odkhuu, D., Giant Perpendicular Magnetic Anisotropy of an Individual Atom on TwoDimensional Transition Metal Dichalcogenides. Phys. Rev. B 2016, 94, 060403.

6. Saber, M. R.; Dunbar, K. R., Ligands Effects on the Magnetic Anisotropy ff Tetrahedral Cobalt Complexes. Chem. Commun. 2014, 50, 12266-12269.

7. Singh, S. K.; Rajaraman, G., Deciphering the Origin of Giant Magnetic Anisotropy and Fast Quantum Tunnelling in Rhenium(IV) Single-Molecule Magnets. Nature Communications 2016, 7, 10669.

8. $\quad$ Bairagi, K.; lasco, O.; Bellec, A.; Kartsev, A.; Li, D.; Lagoute, J.; Chacon, C.; Girard, Y.; Rousset, S.; Miserque, F., et al., Molecular-Scale Dynamics of Light-Induced Spin Cross-Over in a Two-Dimensional Layer. Nature Communications 2016, 7, 12212.

9. Bousseksou, A.; Molnar, G.; Salmon, L.; Nicolazzi, W., Molecular Spin Crossover Phenomenon: Recent Achievements and Prospects. Chem. Soc. Rev. 2011, 40, 3313-3335.

10. Gruber, M.; Davesne, V.; Bowen, M.; Boukari, S.; Beaurepaire, E.; Wulfhekel, W.; Miyamachi, T., Spin State of Spin-Crossover Complexes: From Single Molecules to Ultrathin Films. Phys. Rev. B 2014, 89, 195415.

11. Halcrow, M. A., Structure: Function Relationships in Molecular Spin-Crossover Complexes. Chem. Soc. Rev. 2011, 40, 4119-4142.

12. Hauser, A., Light-Induced Spin Crossover and the High-Spin $\rightarrow$ Low-Spin Relaxation. In Spin Crossover in Transition Metal Compounds II, Springer Berlin Heidelberg: Berlin, Heidelberg, 2004; pp 155-198.

13. Kohn, W., Theory of Insulating State. Physical Review 1964, 133, A171-A181.

14. Moreno, M.; Barriuso, M. T.; Aramburu, J. A.; Garcia-Fernandez, P.; Garcia-Lastra, J. M., Microscopic Insight into Properties and Electronic Instabilities of Impurities in Cubic and Lower Symmetry Insulators: the Influence of Pressure. J. Phys.: Condens. Matter 2006, 18, R315-R360. 15. Brik, M. G.; Kumar, G. A.; Sardar, D. K., Ab Initio, Crystal Field and Experimental Spectroscopic Studies of Pure and $\mathrm{Ni}^{2+}$-Doped $\mathrm{KZnF}_{3}$ Crystals. Mater. Chem. Phys. 2012, 136, 90102.

16. Garcia-Lastra, J. M.; Wesolowski, T.; Barriuso, M. T.; Aramburu, J. A.; Moreno, M., Optical and Vibrational Properties of $\mathrm{MnF}_{6}{ }^{4-}$ Complexes in Cubic Fluoroperovskites: Insight Through Embedding Calculations Using Kohn-Sham Equations with Constrained Electron Density. J. Phys.: Condens. Matter 2006, 18, 1519.

17. Goldberg, V.; Moncorgé, R.; Pacheco, D.; Di Bartolo, B., Fluorescence Studies of Concentrated $\mathrm{Mn}^{2+}$ Systems. In Luminescence of Inorganic Solids, Di Bartolo, B.; Godberg, V.; Pacheco, D., Eds. Springer US: Boston, MA, 1978; pp 603-625.

18. Knox, K.; Shulman, R. G.; Sugano, S., Covalency Effects in $\mathrm{KNF}_{3}$. II. Optical Studies. Physical Review 1963, 130, 512-516. 
19. Rodriguez, F.; Moreno, M.; Tressaud, A.; Chaminade, J. P., $\mathrm{Mn}^{2+}$ in Cubic Perovskites Determination of the $\mathrm{Mn}^{2+}-\mathrm{F}^{-}$Distance from the Optical-Spectrum. Crystal Lattice Defects and Amorphous Materials 1987, 16, 221-225.

20. Villacampa, B.; Cases, R.; Orera, V. M.; Alcalá, R., EPR and Optical Study of $\mathrm{Ni}^{2+}$ Ions in $\mathrm{CsCaF}_{3}$ and $\mathrm{CsCdF}_{3}$. J. Phys. Chem. Solids 1994, 55, 263-272.

21. Brik, M. G.; Ogasawara, K., Microscopic Analysis of the Crystal Field Strength and Lowest Charge Transfer Energies in the Elpasolite Crystals $\mathrm{Cs}_{2} \mathrm{NaYX}_{6}(\mathrm{X}=\mathrm{F}, \mathrm{Cl}, \mathrm{Br})$ Doped with $\mathrm{Cr}^{3+}$. Phys. Rev. B 2006, 74, 045105.

22. De Lucas, M. C. M.; Dance, J. M.; Rodríguez, F.; Tressaud, A.; Moreno, M.; Grannec, J., Spectroscopic Study of $\mathrm{Cr}^{3+}$ in New Elpasolites. Radiat Eff. Defects Solids 1995, 135, 19-22.

23. Dolan, J. F.; Rinzler, A. G.; Kappers, L. A.; Bartram, R. H., Pressure and Temperature Dependence of Chromium Photoluminescence Spectra in Fluoride Elpasolites. J. Phys. Chem. Solids 1992, 53, 905-912.

24. Garcia-Lastra, J. M.; Moreno, M.; Barriuso, M. T., Pressure Effects on $\mathrm{CrCl}_{6}{ }^{3-}$ Embedded In Cubic $\mathrm{Cs}_{2} \mathrm{NaMCl}_{6}(\mathrm{M}=\mathrm{Sc}, \mathrm{Y})$ Lattices: Study Through Periodic And Cluster Calculations. J. Chem. Phys. 2008, 128, 144708.

25. Güdel, H. U.; Snellgrove, T. R., Jahn-Teller Effect in the ${ }^{4} \mathrm{~T}_{2 \mathrm{~g}}$ state of Chromium(III) in Dicesium Sodium Indium(III) Hexachloride. Inorg. Chem. 1978, 17, 1617-1620.

26. Tanner, P. A., Fluorescence and Phosphorescence of $\mathrm{Cr}^{3+}$ in Cubic Hosts. Chem. Phys. Lett. 2004, 388, 488-493.

27. Woods, A. M.; Sinkovits, R. S.; Charpie, J. C.; Huang, W. L.; Bartram, R. H.; Rossi, A. R., Computer Modeling of the Optical Properties of Substitutional Chromium Impurities in Halide Elpasolites. J. Phys. Chem. Solids 1993, 54, 543-552.

28. Burns, R. G., Mineralogical Applications of Crystal Field Theory. Cambridge University Press: Cambridge, 1993.

29. Powell, R. C., Physics of Solid State Laser Materials. Springer: New York, 1998.

30. Aramburu, J. A.; Garcia-Fernandez, P.; García-Lastra, J. M.; Barriuso, M. T.; Moreno, M., Internal Electric Fields and Color Shift in $\mathrm{Cr}^{3+}$-Based Gemstones. Phys. Rev. B 2012, 85, 245118.

31. Gaudry, E.; Cabaret, D.; Brouder, C.; Letard, I.; Rogalev, A.; Wilhlem, F.; Jaouen, N.; Sainctavit, P., Relaxations Around the Substitutional Chromium Site in Emerald: X-Ray Absorption Experiments and Density Functional Calculations. Phys. Rev. B 2007, 76, 094110.

32. Gaudry, E.; Kiratisin, A.; Sainctavit, P.; Brouder, C.; Mauri, F.; Ramos, A.; Rogalev, A.; Goulon, J., Structural and Electronic Relaxations Around Substitutional $\mathrm{Cr}^{3+}$ and $\mathrm{Fe}^{3+}$ Ions in Corundum. Phys. Rev. B 2003, 67, 094108.

33. Aramburu, J. A.; Garcia-Fernandez, P.; Garcia-Lastra, J. M.; Barriuso, M. T.; Moreno, M., Colour Due to $\mathrm{Cr}^{3+}$ Ions in Oxides: a Study of the Model System MgO: $\mathrm{Cr}^{3+}$. J. Phys.: Condens. Matter 2013, 25, 175501

34. Dance, J. M., Nature of the Jahn-Teller Cooperative Effect in Alkaline-Earth Fluorides $\mathrm{ACuF}_{4}$ - Influence on Magnetic-Properties. Mater. Res. Bull. 1981, 16, 599-606.

35. Reinen, D.; Atanasov, M.; Nikolov, G.; Steffens, F., Local and Cooperative Jahn-Teller Distortions of Nickel(2+) and Copper (2+) in Tetrahedral Coordination. Inorg. Chem. 1988, 27, 1678-1686.

36. von Schnering, H. G.; Kolloch, B.; Kolodzie.A, Structure of Ternary Copper(II) and Chromium(II) Fluorides. Angew. Chem., Int. Ed. 1971, 10, 413-+.

37. Steffen, G.; Reinen, D.; Stratemeier, H.; Riley, M. J.; Hitchman, M. A.; Matthies, H. E.; Recker, K.; Wallrafen, F.; Niklas, J. R., EPR and ENDOR Spectra of Copper(II) Centers with $d_{z 2}$ and $\mathrm{d}_{\mathrm{xz}-\mathrm{y} 2}$ Ground-States in $\mathrm{Ba}_{2} \mathrm{ZnF}_{6}$ - Analysis of Hyperfine Parameters and Dynamic Vibronic Coupling. Inorg. Chem. 1990, 29, 2123-2131.

38. von Schnering, H. G., Kristallstrukturen der Bariumfluorometallate(II) $\mathrm{Ba}_{2} \mathrm{MF}_{6}$ mit $\mathrm{M}=$ $\mathrm{Zn}, \mathrm{Cu}, \mathrm{Ni}, \mathrm{Co}, \mathrm{Fe}$. Z. Anorg. Allg. Chem. 1967, 353, 13-25. 
39. Reinen, D.; Steffen, G.; Hitchman, M. A.; Stratemeier, H.; Dubicki, L.; Krausz, E. R.; Riley, M. J.; Mathies, H. E.; Recker, K.; Wallrafen, F., The Optical-Spectrum of $\mathrm{Ba}_{2} \mathrm{ZnCuF}_{6}$. Chem. Phys. 1991, 155, 117-125.

40. Aramburu, J. A.; García-Fernández, P.; García-Lastra, J. M.; Moreno, M., Jahn-Teller and Non-Jahn-Teller Systems Involving $\mathrm{CuF}_{6}{ }^{4-}$ Units: Role of the Internal Electric Field in $\mathrm{Ba}_{2} \mathrm{ZnF}_{6}: \mathrm{Cu}^{2+}$ and Other Insulating Systems. The Journal of Physical Chemistry C 2017, 121, 5215-5224.

41. Dovesi, R.; Orlando, R.; Erba, A.; Zicovich-Wilson, C. M.; Civalleri, B.; Casassa, S.; Maschio, L.; Ferrabone, M.; De La Pierre, M.; D'Arco, P., et al., CRYSTAL14: A Program for the Ab Initio Investigation of Crystalline Solids. Int. J. Quantum Chem. 2014, 114, 1287-1317.

42. CRYSTAL basis sets http://www.crystal.unito.it/basis-sets.php (accessed 02/09/2017).

43. Peintinger, M. F.; Oliveira, D. V.; Bredow, T., Consistent Gaussian Basis Sets of TripleZeta Valence with Polarization Quality for Solid-State Calculations. J. Comput. Chem. 2013, 34, 451-459.

44. Bilc, D. I.; Orlando, R.; Shaltaf, R.; Rignanese, G. M.; Iniguez, J.; Ghosez, P., Hybrid Exchange-Correlation Functional for Accurate Prediction of the Electronic and Structural Properties of Ferroelectric Oxides. Phys. Rev. B 2008, 77, 165107.

45. Bredow, T.; Gerson, A. R., Effect of Exchange and Correlation on Bulk Properties of MgO, $\mathrm{NiO}$, and CoO. Phys. Rev. B 2000, 61, 5194-5201.

46. Burow, A. M.; Sierka, M.; Döbler, J.; Sauer, J., Point Defects in $\mathrm{CaF}_{2}$ and $\mathrm{CeO}_{2}$ Investigated by the Periodic Electrostatic Embedded Cluster Method. J. Chem. Phys. 2009, 130, 174710.

47. Jug, K.; Bredow, T., Models for the Treatment of Crystalline Solids and Surfaces. J. Comput. Chem. 2004, 25, 1551-1567.

48. Gutdeutsch, U.; Birkenheuer, U.; Krüger, S.; Rösch, N., On Cluster Embedding Schemes Based on Orbital Space Partitioning. J. Chem. Phys. 1997, 106, 6020-6030.

49. Wesołowski, T. A., Embedding a Multideterminantal Wave Function in an Orbital-Free Environment. Physical Review A 2008, 77, 012504.

50. Barandiarán, Z.; Seijo, L., The Ab Initio Model Potential Representation of the Crystalline Environment. Theoretical Study of the Local Distortion on $\mathrm{NaCl}: \mathrm{Cu}^{+}$. J. Chem. Phys. 1988, 89, 5739-5746.

51. Sherwood, P.; de Vries, A. H.; Guest, M. F.; Schreckenbach, G.; Catlow, C. R. A.; French, S. A.; Sokol, A. A.; Bromley, S. T.; Thiel, W.; Turner, A. J., et al., QUASI: A General Purpose Implementation of the QM/MM Approach and its Application to Problems in Catalysis. Journal of Molecular Structure: THEOCHEM 2003, 632, 1-28.

52. Velde, G. T.; Bickelhaupt, F. M.; Baerends, E. J.; Guerra, C. F.; Van Gisbergen, S. J. A.; Snijders, J. G.; Ziegler, T., Chemistry with ADF. J. Comput. Chem. 2001, 22, 931-967.

53. Becke, A. D., Density - Functional Thermochemistry. III. The Role of Exact Exchange. J. Chem. Phys. 1993, 98, 5648-5652.

54. Tosi, M. P., Cohesion of Ionic Solids in the Born Model. Solid State Physics 1964, 16, 1120.

55. Van Gool, W.; Piken, A. G., Lattice Self-Potentials and Madelung Constants for Some Compounds. Journal of Materials Science 1969, 4, 95-104.

56. Aramburu, J. A.; Moreno, M., Bonding in $\mathrm{d}^{9}$ Complexes Derived from EPR: Application to $\mathrm{CuCl}_{4}{ }^{2-}, \mathrm{CuBr}_{4}{ }^{2-}$, and $\mathrm{CdCl}_{2}: \mathrm{Cu}^{2+}$. J. Chem. Phys. 1985, 83, 6071-6083.

57. Borcherts, R. H.; Kanzaki, H.; Abe, H., EPR Spectrum of a Jahn-Teller System, $\mathrm{NaCl}-\mathrm{Cu}^{2+}$. Phys. Rev. B 1970, 2, 23-+.

58. Hayashi, M.; Nakagawa, H.; Matsumoto, H., The Jahn-Teller Center in Cadmium Halide Crystals. I. Copper(II) Chloride-Doped Cadmium Chloride. Memoirs of the Faculty of Engineering, Fukui University 1978, 26, 15-27.

59. Cassidy, P.; Hitchman, M. A., Molecular g Values of the Planar Tetrachlorocuprate(2-) Ion. Inorg. Chem. 1977, 16, 1568-1570.

60. Chow, C.; Chang, K.; Willett, R. D., Electron Spin Resonance Spectra and Covalent Bonding in The Square - Planar $\mathrm{CuCl}_{4}{ }^{2-}$ and $\mathrm{CuBr}_{4}{ }^{2-}$ ions. J. Chem. Phys. 1973, 59, 2629-2640. 
61. Minner, E.; Lovy, D.; Bill, H., Electron-Paramagnetic-Resonance and Relaxation Study of Copper(II) and Silver(II) In $\mathrm{CsCdF}_{3}$ Single-Crystals. J. Chem. Phys. 1993, 99, 6378-6383.

62. Minner, E. M. C. Ph.D. Thesis: Etude Spectroscopique des lons Jahn-Teller Cuivre et Argent Bivalents dans des Monocristaux de Fluoroperovskites de Composition Chimique $\mathrm{AMF}_{3}$. University of Geneva, 1993.

63. Aramburu, J. A.; Garcia-Lastra, J. M.; Garcia-Fernandez, P.; Barriuso, M. T.; Moreno, M., $\mathrm{Cu}^{2+}$ in Layered Compounds: Origin of the Compressed Geometry in the Model System $\mathrm{K}_{2} \mathrm{ZnF}_{4}: \mathrm{Cu}^{2+}$. Inorg. Chem. 2013, 52, 6923-6933.

64. Jørgensen, C. K., Modern Aspects of Ligand Field Theory. North-Holland Pub. Co.: Amsterdam, 1971.

65. Aramburu, J. A.; Moreno, M.; Bencini, A., Charge-Transfer Transitions in $\mathrm{CuCu}_{4}{ }^{2-}$ and $\mathrm{CuBr}_{4}{ }^{2-}$ Complexes: Dependence on the Metal-Ligand Distance. Chem. Phys. Lett. 1987, 140, 462-467.

66. Desjardins, S. R.; Penfield, K. W.; Cohen, S. L.; Musselman, R. L.; Solomon, E. I., Detailed Absorption, Reflectance, and UV Photoelectron Spectroscopic and Theoretical Studies of the Charge-Transfer Transitions of Tetrachlorocuprate(2-) Ion: Correlation of the Square-Planar and the Tetrahedral Limits. J. Am. Chem. Soc. 1983, 105, 4590-4603.

67. Accorsi, G.; Verri, G.; Bolognesi, M.; Armaroli, N.; Clementi, C.; Miliani, C.; Romani, A., The Exceptional Near-Infrared Luminescence Properties of Cuprorivaite (Egyptian Blue). Chem. Commun. 2009, 3392-3394.

68. Ford, R. J.; Hitchman, M. A., Single Crystal Electronic and EPR Spectra of $\mathrm{CaCuSi}_{4} \mathrm{O}_{10}$, a Synthetic Silicate Containing Copper(II) in a Four-Coordinate, Planar Ligand Environment. Inorg. Chim. Acta 1979, 33, L167-L170.

69. Garcia-Fernandez, P.; Moreno, M.; Aramburu, J. A., Origin of the Exotic Blue Color of Copper-Containing Historical Pigments. Inorg. Chem. 2015, 54, 192-199.

70. Henderson, B.; Imbusch, G. F., Optical Spectroscopy of Inorganic Solids. Clarendon Press: Oxford, 2006.

71. García-Lastra, J. M.; García-Fernández, P.; Barriuso, M. T.; Aramburu, J. A.; Moreno, M., Sharp Lines Due to $\mathrm{Cr}^{3+}$ and $\mathrm{Mn}^{2+}$ Impurities in Insulators: Going Beyond the Usual TanabeSugano Approach. The Journal of Physical Chemistry A 2014, 118, 2377-2384.

72. Pierloot, K.; Van Praet, E.; Vanquickenborne, L. G., The Effect of the Crystal Environment on the Metal-Ligand Interaction and the Ligand Field Spectrum of $\mathrm{CrF}_{6}{ }^{3-}$. J. Chem. Phys. 1992, 96, 4163-4170.

73. Riley, M. J.; Hitchman, M. A.; Reinen, D., Effects of Vibronic Coupling on the ElectronParamagnetic-Res Spectra of Copper(II) Doped K2ZnF 4 . Chem. Phys. 1986, 102, 11-28.

74. Garcia-Fernandez, P.; Teresa Barriuso, M.; Garcia-Lastra, J. M.; Moreno, M.; Antonio Aramburu, J., Compounds Containing Tetragonal $\mathrm{Cu}^{2+}$ Complexes: Is the $\mathrm{d}_{x 2-y 2-\mathrm{d}_{322-\mathrm{r} 2}}$ Gap a Direct Reflection of the Distortion? J. Phys. Chem. Lett. 2013, 4, 2385-2390.

75. Riley, M. J.; Dubicki, L.; Moran, G.; Krausz, E. R.; Yamada, I., Absorption and Magnetic Circular-Dichroism Spectra of the Compressed Copper(II) Ion in $\mathrm{K}_{2} \mathrm{ZnF}_{4}$. Chem. Phys. 1990, 145, 363-373.

76. Dubicki, L.; Riley, M. J.; Krausz, E. R., Electronic-Structure of the Copper(II) lon Doped in Cubic KZnF 3 . J. Chem. Phys. 1994, 101, 1930-1938.

77. Rodriguez, F., Unveiling the Local Structure of $\mathrm{Cu}^{2+}$ Ions from d-Orbital Splitting. Application to $\mathrm{K}_{2} \mathrm{ZnF}_{4}: \mathrm{Cu}^{2+}$ and $\mathrm{KZnF}_{3}: \mathrm{Cu}^{2+}$. Inorg. Chem. 2017.

78. Garcia-Lastra, J. M.; Aramburu, J. A.; Barriuso, M. T.; Moreno, M., Impurities in Noncubic Crystals: Stabilization Mechanisms for Jahn-Teller lons in Layered Perovskites. Phys. Rev. Lett. 2004, 93, 226402

79. Alcalá, R.; Zorita, E.; Alonso, P. J., Monovalent Nickel in $\mathrm{K}_{2} \mathrm{MgF}_{4}$ : An EPR Investigation. Journal of Physics C: Solid State Physics 1988, 21, 461. 
80. Trueba, A.; Garcia-Fernandez, P.; Garcia-Lastra, J. M.; Aramburu, J. A.; Barriuso, M. T.; Moreno, M., Spectrochemical Series and the Dependence of Racah and 10Dq Parameters on the Metal-Ligand Distance: Microscopic Origin. J. Phys. Chem. A 2011, 115, 1423-1432.

81. McDonald, R. G.; Hitchman, M. A., Electronic "d-d" Spectra of the Planar Tetrachlorocuprate(2-) lons in Bis(Methadonium) Tetrachlorocuprate(li) and Bis(Creatininium) Tetrachlorocuprate(li): Analysis of the Temperature Dependence ans Vibrational Fine Structure. Inorg. Chem. 1986, 25, 3273-3281.

82. Bravo, D.; Bottcher, R., Electron-Nuclear Double-Resonance Investigations on $\mathrm{Cr}^{3+}$ Ions in Natural $\mathrm{MgAl}_{2} \mathrm{O}_{4}$ Spinel. J. Phys.: Condens. Matter 1992, 4, 7295-7306.

83. Jeck, R. K.; Krebs, J. J., First-Shell and Second-Shell Hyperfine Interactions in Iron-GroupDoped Perovskite Fluorides. Phys. Rev. B 1972, 5, 1677-\&.

84. Laurance, N.; Mclrvine, E. C.; Lambe, J., Aluminum Hyperfine Interactions in Ruby. J. Phys. Chem. Solids 1962, 23, 515-\&.

85. Davydov, A., Theory of Molecular Excitons. Springer US: New York, 2013.

86. Trueba, A.; Garcia-Lastra, J. M.; Barriuso, M. T.; Aramburu, J. A.; Moreno, M., Influence of Internal Electric Fields on Bonding and Properties of Impurities in Insulators: $\mathrm{Mn}^{2+}$ in $\mathrm{LiBaF}_{3}$ and Normal Perovskites. Phys. Rev. B 2008, 78, 075108.

87. Ghica, D.; Nistor, S. V.; Vrielinck, H.; Callens, F.; Schoemaker, D., $X$ and $Q$ band ENDOR Study of the $\mathrm{Fe}^{+} \mathrm{Center}$ in Chlorinated $\mathrm{SrCl}_{2}: \mathrm{Fe}$ crystals. Phys. Rev. B 2004, 70, 024105.

88. Nistor, S. V.; Stefan, M.; Schoemaker, D., Off-Center Displacement of $\mathrm{Fe}^{+}$lons in Irradiated $\mathrm{SrCl}_{2}$ : Fe Crystals Grown in Chlorine. physica status solidi (b) 1999, 214, 229-236.

89. Garcia-Fernandez, P.; Senn, F.; Daul, C. A.; Aramburu, J. A.; Barriuso, M. T.; Moreno, M., The Giant Magnetic Anisotropy Energy of $\mathrm{Fe}^{+}$lons in $\mathrm{SrCl}_{2}$. PCCP 2009, 11, 7545-7548.

90. Garcia-Fernandez, P.; Moreno, M.; Aramburu, J. A., Electrostatic Control of Orbital Ordering in Noncubic Crystals. J. Phys. Chem. C 2014, 118, 7554-7561.

91. Cai, D.; Marques, M. A. L.; Nogueira, F., Full Color Modulation of Firefly Luciferase through Engineering with Unified Stark Effect. The Journal of Physical Chemistry B 2013, 117, 13725-13730.

92. Fujimoto, K.; Hasegawa, J.-y.; Nakatsuji, H., Origin of Color Tuning in Human Red, Green, and Blue Cone Pigments: SAC-Cl and QM/MM Study. Chem. Phys. Lett. 2008, 462, 318-320.

93. Ridou, C.; Rousseau, M.; Bouillot, J.; Vettier, C., Anharmonicity in Fluoperovskites. Journal of Physics C-Solid State Physics 1984, 17, 1001-1007. 

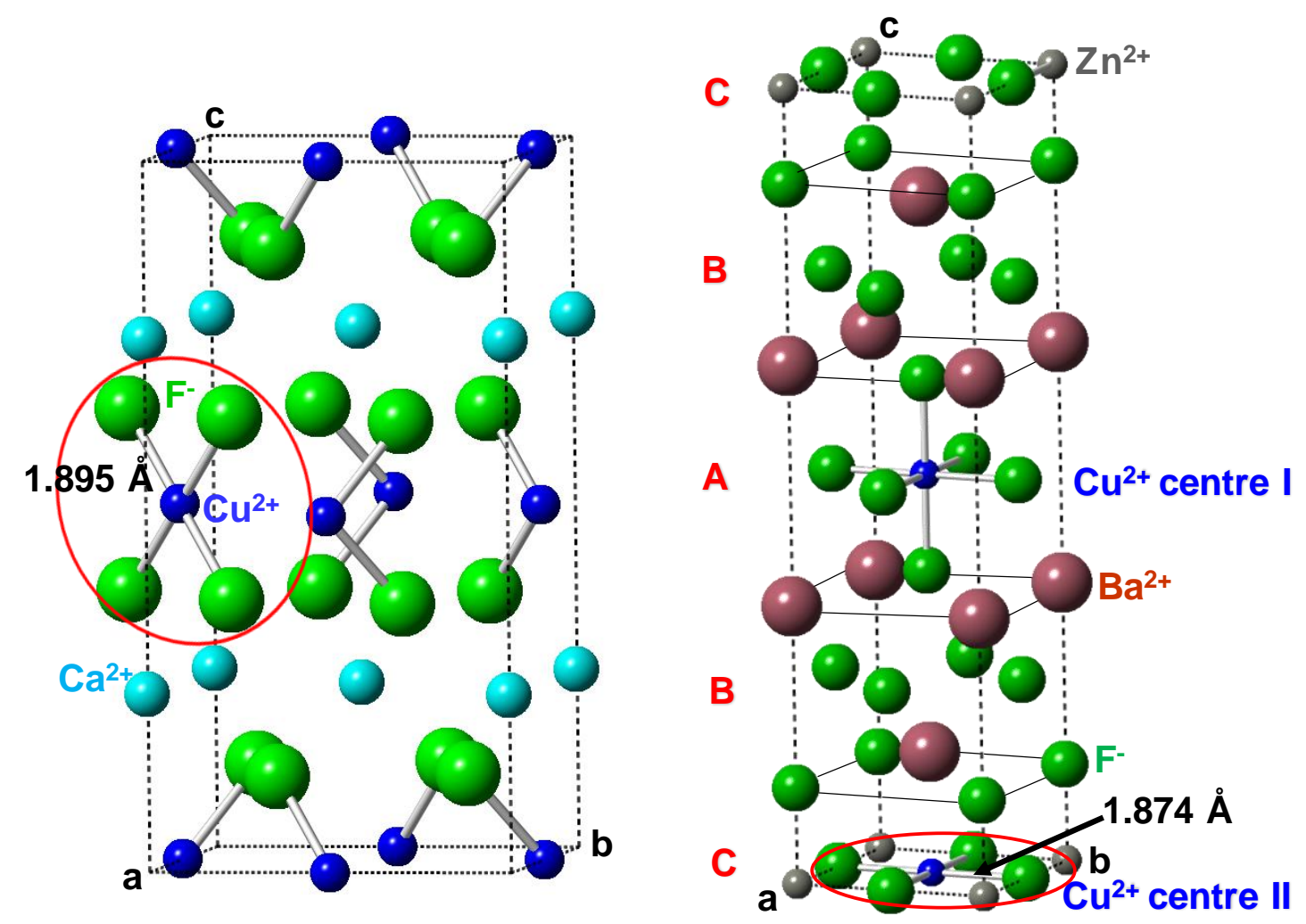

Figure 1. Left: Crystal structure of the tetragonal $\mathrm{CaCuF}_{4}$ material with square-planar $\mathrm{CuF}_{4}{ }^{2-}$ units. Right: Crystal structure of the tetragonal layered perovskite $\mathrm{Ba}_{2} \mathrm{ZnF}_{6}$ (layer sequence $A B C A B C . .$.$) showing the two \mathrm{Cu}^{2+}$ centers, center I with a tetragonally compressed $\mathrm{CuF}_{6}{ }^{4-}$ complex and center II with a square-planar $\mathrm{CuF}_{4}{ }^{2-}$ unit. 


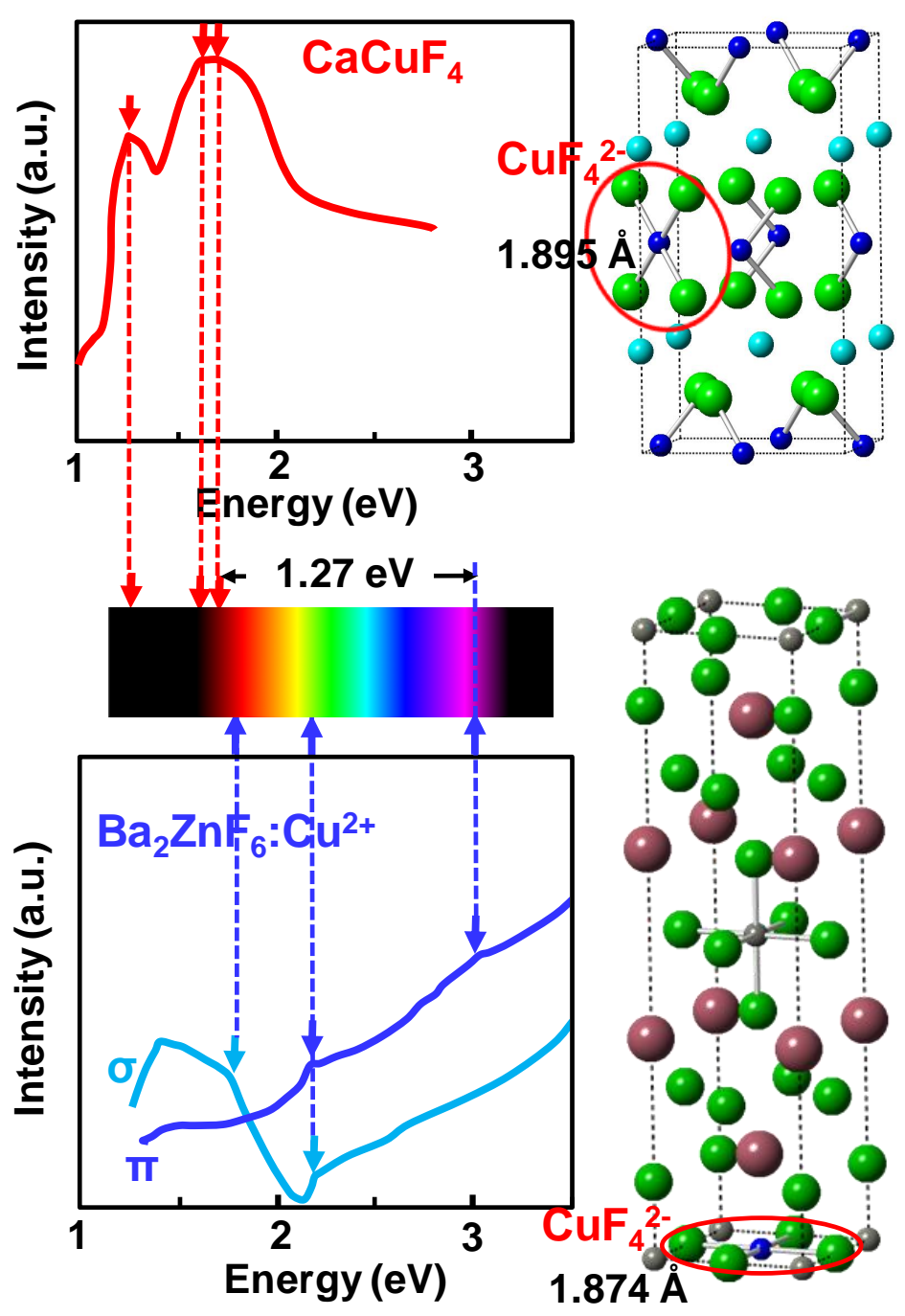

Figure 2. Experimental peak positions at $T=5 \mathrm{~K}$ of the three $\mathrm{d}$ - $\mathrm{d}$ transitions (marked with arrows) corresponding to square-planar $\mathrm{CuF}_{4}{ }^{2-}$ units in $\mathrm{CaCuF}_{4}$ (in top and red line, electronic reflectance spectrum taken from Ref. [36]). This spectrum is compared with the transitions associated with the center II in $\mathrm{Ba}_{2} \mathrm{ZnF}_{6}: \mathrm{Cu}^{2+}$, observed, at $\mathrm{T}=5 \mathrm{~K}$, as shoulders in the polarized optical absorption spectra given in the bottom. Results for this system are taken from Ref. ${ }^{39}$ where data in $\sigma$-polarization are shown in light blue color while those in $\pi$-polarization are indicated in dark blue color. The peak at around $1.6 \mathrm{eV}$ in $\sigma$-polarization corresponds to the highest $d$ - $d$ transition $\left(x y \rightarrow 3 z^{2}-r^{2}\right.$ ) of the compressed $\mathrm{CuF}_{6}{ }^{4-}$ unit in $\mathrm{Ba}_{2} \mathrm{ZnF}_{6}$ (center I). The identification of the $\mathrm{d}$ - $\mathrm{d}$ transitions, all above $1.60 \mathrm{eV}$, corresponding to square-planar $\mathrm{CuF}_{4}{ }^{2-}$ complexes is helped by the fact that the only three $d-d$ peaks of octahedral $\mathrm{CuF}_{6}{ }^{4-}$ units ${ }^{39-40}$, the dominant species formed in doped $\mathrm{Ba}_{2} \mathrm{ZnF}_{6}$, appear in the range $0.80-1.60 \mathrm{eV}$. 

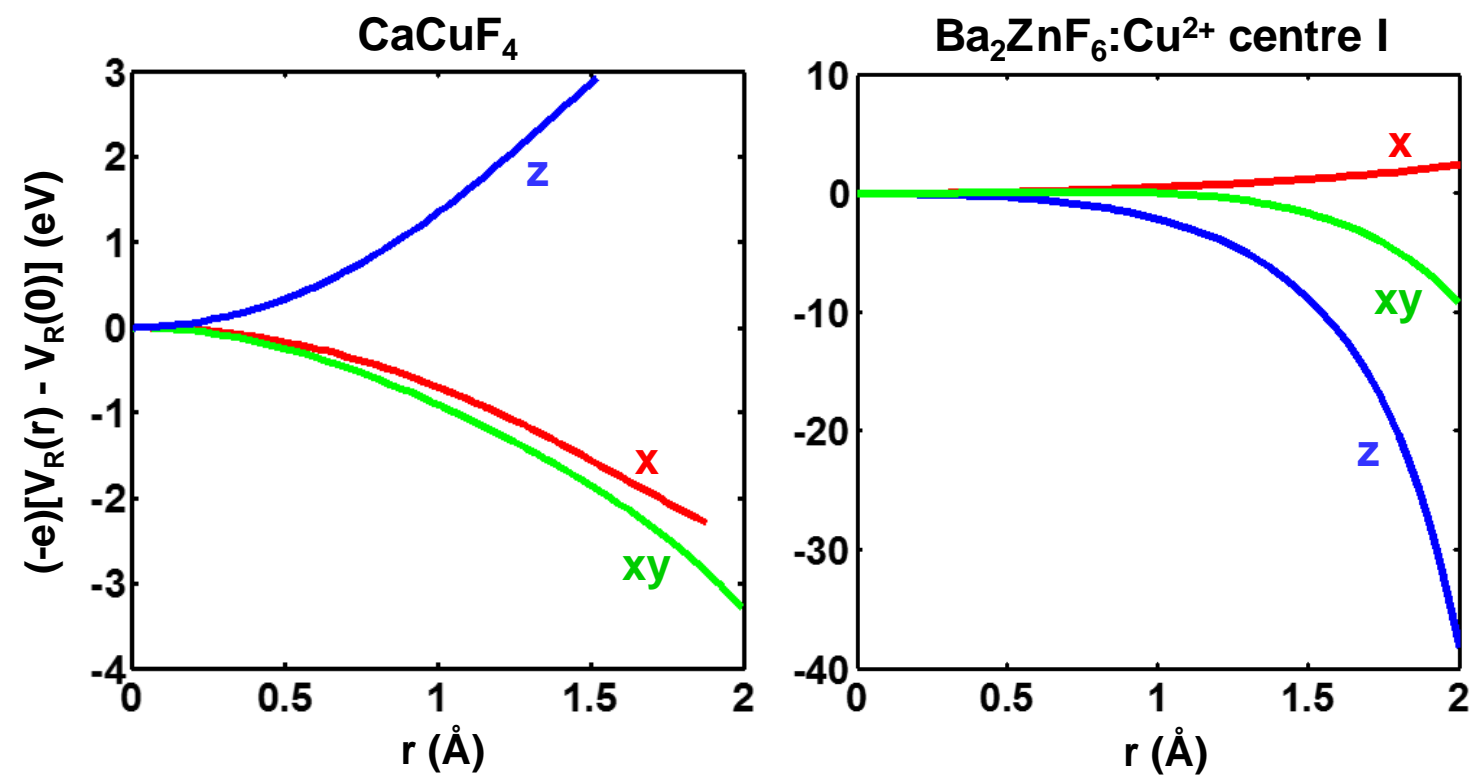

Figure 3. Potential energy $(-e)\left[\mathrm{V}_{R}(\mathbf{r})-\mathrm{V}_{\mathrm{R}}(0)\right]$ for the $\mathrm{CuF}_{4}{ }^{2-}$ complexes in $\mathrm{CaCuF}_{4}$ and $\mathrm{Ba}_{2} \mathrm{ZnF}_{6}: \mathrm{Cu}^{2+}$ (center I) along the directions $\mathrm{Cu}-\mathrm{F}(\mathrm{x})$, diagonal in the complex plane (xy) and perpendicular to the complex plane $(z)$. 


\begin{tabular}{lcccc}
\hline System & Complex & g国 & $g_{\text {[■ }}$ & Ref. \\
\hline $\mathrm{NaCl}: \mathrm{Cu}^{2+}$ & $\mathrm{CuCl}_{6}^{4-}$ & 2.37 & 2.07 & 57 \\
$\mathrm{CdCl}_{2}: \mathrm{Cu}^{2+}$ & $\mathrm{CuCl}_{6}^{4-}$ & 2.34 & 2.07 & 58 \\
$(\mathrm{~N}-\mathrm{mpH})_{2} \mathrm{CuCl}_{4}$ & $\mathrm{CuCl}_{4}{ }^{2-}$ & 2.22 & 2.04 & 59 \\
$\mathrm{~K}_{2} \mathrm{PdCl}_{4}: \mathrm{Cu}^{2+}$ & $\mathrm{CuCl}_{4}{ }^{2-}$ & 2.23 & 2.05 & 60 \\
$\mathrm{KZnF}_{3}: \mathrm{Cu}^{2+}$ & $\mathrm{CuF}_{6}{ }^{4-}$ & 2.57 & 2.14 & 62 \\
$\mathrm{CsCdF}_{3}: \mathrm{Cu}^{2+}$ & $\mathrm{CuF}_{6}{ }^{4-}$ & 2.65 & 2.12 & 61 \\
$\mathrm{Ba}_{2} \mathrm{ZnF}_{4}: \mathrm{Cu}^{2+}(\mathrm{II})$ & $\mathrm{CuF}_{4}{ }^{2-}$ & 2.43 & 2.07 & 37 \\
$\mathrm{CaCuF}_{4}$ & $\mathrm{CuF}_{4}{ }^{2-}$ & 2.47 & 2.07 & 35 \\
\hline
\end{tabular}

Table 1. Experimental $g$-tensor measured for $\mathrm{CuXX}_{6}{ }^{4-}$ and $\mathrm{CuX}_{4}{ }^{2-}$ complexes $(\mathrm{X}=\mathrm{Cl}, \mathrm{F})$ placed in insulating lattices.

\begin{tabular}{cccccc}
\hline & $\mathrm{a}(\AA)$ & $\mathrm{c}(\AA)$ & $\mathrm{R}(\AA)$ & $\mathrm{Ca}-\mathrm{F}(\AA)$ & $\mathrm{F}-\mathrm{Cu}-\mathrm{F}(\stackrel{\circ}{ })$ \\
\hline Calculated & 5.371 & 10.347 & 1.895 & 2.351 & 86.99 \\
Experimental & 5.377 & 10.320 & 1.880 & 2.349 & 89.39 \\
\hline
\end{tabular}

Table 2. Calculated values of some geometrical parameters corresponding to the $\mathrm{CaCuF}_{4}$ compound at equilibrium. $\mathbf{a}$ and $\mathbf{c}$ are the lattice parameters (Fig. 1), R is the $\mathrm{Cu}^{2+}-\mathrm{F}^{-}$ distance, $\mathrm{Ca}-\mathrm{F}$ the distance between a $\mathrm{F}^{-}$ligand of $\mathrm{CuF}_{4}{ }^{2-}$ and the nearest $\mathrm{Ca}^{2+}$ ion and $\mathrm{F}$ $\mathrm{Cu}-\mathrm{F}$ the corresponding angle. Experimental results ${ }^{36}$, obtained at room temperature, are collected for comparison. As the linear thermal expansion coefficient, $\alpha$, is practically zero for a fluoride like $\mathrm{KZnF}_{3}$ below $\sim 100 \mathrm{~K}$ and equal to $1.510^{-5} \mathrm{~K}^{-1}$ at room temperature ${ }^{93}$ the increase of $\mathrm{R}$ on passing from $\mathrm{T}=0 \mathrm{~K}$ to room temperature for $\mathrm{CaCuF}_{4}$ is expected to be less than $0.01 \AA$. Thus the present comparison between the calculated $\mathrm{R}$ value at $\mathrm{T}=0 \mathrm{~K}$ for $\mathrm{CaCuF}_{4}$ and that measured at $\mathrm{T}=300 \mathrm{~K}$ makes sense. 


\begin{tabular}{cccc}
\hline $\mathrm{M}$ & $\mathrm{M}-\mathrm{F}$ & $\mathrm{M}-\mathrm{Ba}$ & $\mathrm{M}-\mathrm{Zn}$ \\
\hline Interstitial site & 2.055 & 2.455 & 2.90 \\
$\mathrm{Cu}^{2+}$ impurity & 1.874 & 3.00 & 3.06 \\
\hline
\end{tabular}

Table 3. Distances (in $\AA$ units) from the interstitial site in a layer $\mathrm{C}$ of the perfect $\mathrm{Ba}_{2} \mathrm{ZnF}_{4}$ lattice to the four nearest $\mathrm{F}^{-}$and four nearest $\mathrm{Zn}^{2+}$ ions in the layer plane as well as to the two axial $\mathrm{Ba}^{2+}$. These distances are compared with the corresponding ones calculated when the interstitial site is occupied by a $\mathrm{Cu}^{2+}$ impurity. In $\mathrm{Ba}_{2} \mathrm{ZnF}_{4}$ the experimental distances among ions ${ }^{38}$, measured at room temperature, are affected by an error of $\pm 0.02 \AA$.

\begin{tabular}{cccc}
\hline Transition & Isolated $\mathrm{CuF}_{4}{ }^{2-}$ & $\mathrm{CuF}_{4}{ }^{2-}$ under $\mathrm{E}_{\mathrm{R}}(\mathbf{r})$ & Experim. \\
\hline $\mathrm{b}_{2 \mathrm{~g}}(\mathrm{xy})$ ? $\mathrm{b}_{1 \mathrm{~g}}\left(\mathrm{x}^{2}-\mathrm{y}^{2}\right)$ & 1.55 & 1.37 & 1.25 \\
$\mathrm{e}_{\mathrm{g}}(\mathrm{xz}, \mathrm{yz})$ 回 $\mathrm{b}_{1 \mathrm{~g}}\left(\mathrm{x}^{2}-\mathrm{y}^{2}\right)$ & 2.13 & 1.80 & 1.65 \\
$\mathrm{a}_{1 \mathrm{~g}}\left(3 \mathrm{z}^{2}-\mathrm{r}^{2}\right)$ 回 $\mathrm{b}_{1 \mathrm{~g}}\left(\mathrm{x}^{2}-\mathrm{y}^{2}\right)$ & 2.58 & 1.84 & 1.71 \\
\hline
\end{tabular}

Table 4. Energy values (in eV) of three $d$ - $d$ transitions for $\mathrm{CuF}_{4}{ }^{2-}$ in $\mathrm{CaCuF}_{4}$ calculated for a metal-ligand distance $R=1.89 \AA$. In a first step, the three transitions have been derived considering only the isolated complex at the right equilibrium geometry. In a second step, the influence of the internal electric field generated by ions of the rest of the lattice on active electrons located in the $\mathrm{CuF}_{4}{ }^{2-}$ complex has also been taken into account. Experimental values ${ }^{35}$ are also reported for comparison.

\begin{tabular}{cccc}
\hline Transition & Isolated $\mathrm{CuF}_{4}{ }^{2-}$ & $\mathrm{CuF}_{4}{ }^{2-}$ under $\mathrm{E}_{\mathrm{R}}(\mathbf{r})$ & Experimental \\
\hline $\mathrm{b}_{2 \mathrm{~g}}(\mathrm{xy})$ 回 $\mathrm{b}_{1 \mathrm{~g}}\left(\mathrm{x}^{2}-\mathrm{y}^{2}\right)$ & 1.57 & 1.78 & ? 1.74 \\
$\mathrm{e}_{\mathrm{g}}(\mathrm{xz} ; \mathrm{yz})$ ? $\mathrm{b}_{1 \mathrm{~g}}\left(\mathrm{x}^{2}-\mathrm{y}^{2}\right)$ & 2.16 & 2.19 & ??2.23 \\
$\mathrm{a}_{1 \mathrm{~g}}\left(3 \mathrm{z}^{2}-\mathrm{r}^{2}\right)$ 回 $\mathrm{b}_{1 \mathrm{~g}}\left(\mathrm{x}^{2}-\mathrm{y}^{2}\right)$ & 2.61 & 2.73 & ?2.98 \\
\hline
\end{tabular}

Table 5. Energy values of $d-d$ transitions (in eV) for $\mathrm{CuF}_{4}{ }^{2-}$ in $\mathrm{Ba}_{2} \mathrm{ZnF}_{4}$ calculated for $\mathrm{R}=$ $1.874 \AA$ and compared to experimental findings $\mathrm{s}^{39}$. Aside from results for the isolated complex those obtained including the internal electric field due to the $\mathrm{Ba}_{2} \mathrm{ZnF}_{4}$ lattice are also reported. Note that all transitions are observed as shoulders in optical absorption spectra. In particular, the highest $d$ - $d$ transition appears as a shoulder in a band whose intensity strongly grows when the energy increases. 
For Table of Contents Only

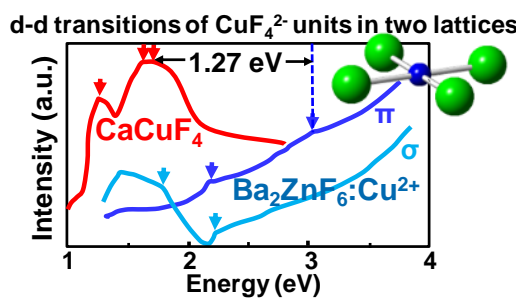

Understanding the huge difference in the $\mathrm{d}$-d transitions (up to $1.27 \mathrm{eV}$ ) in square-planar $\mathrm{CuF}_{4}{ }^{2-}$ units in $\mathrm{CaCuF}_{4}$ material and center II in $\mathrm{Cu}^{2+}$-doped $\mathrm{Ba}_{2} \mathrm{ZnF}_{6}$ requires to consider the anisotropic electric field due to the ions of each lattice. 